\title{
Informational Loss in Bundled Bargaining ${ }^{1}$
}

\author{
Ying Chen \\ Arizona State University \\ yingchen@asu.edu
}

\author{
Hülya Eraslan \\ Johns Hopkins University \\ eraslan@jhu.edu
}

December 18, 2012

${ }^{1}$ We thank an anonymous referee, Keith Dowding (the Editor), John Duggan, Jean Guillaume Forand, Tasos Kalandrakis, Navin Kartik, Ming Li, Ken Shotts, Jack Stecher, Alan Wiseman along with various seminar and conference participants for helpful comments and stimulating conversations. Any errors are our own. 


\begin{abstract}
We analyze a legislative bargaining game over an ideological and a distributive issue. Legislators are privately informed about their ideological positions. Communication takes place before a proposal is offered and majority rule voting determines the outcome. We compare the outcome of the "bundled bargaining" game in which the legislators negotiate over both issues together to that of the "separate bargaining" game in which the legislators negotiate over the issues one at a time. Although bundled bargaining allows the proposer to use transfers as an instrument for compromise on the ideological issue, we identify two disadvantages of bundled bargaining under asymmetric information: (i) risk of losing the surplus (failure to reach agreement on ideology results in the dissipation of the surplus under bundled bargaining, but not under separate bargaining); (ii) informational loss (the legislators may convey less information in the bundled bargaining game). Even when there is no risk of losing the surplus, the informational loss from bundling can be sufficiently large that it makes the proposer worse off.
\end{abstract}




\section{Introduction}

Legislative policy-making typically involves bargaining over multiple issues. In some cases, the issues are not easily separable, so they are decided together. In others there does not seem to be an obvious link between the issues. For example, in the recent health care legislation in the U.S., whether to provide public funding for abortion or not was an issue that seems orthogonal to other provisions in the bill such as whether to ban denial of insurance coverage due to pre-existing conditions. Yet at some point, the passage of the entire health care bill hinged on the abortion language. ${ }^{1}$ One benefit of bundling unrelated issues in bargaining is that it provides more opportunities for legislators to reach compromise. Indeed, in an environment of complete information, Jackson and Moselle (2002) show that negotiating over multiple issues simultaneously is better than negotiating over them separately. However, in practice, legislators often have private information about their preferences. Is bundled bargaining still better than separate bargaining under asymmetric information?

To tackle this question, we introduce a bargaining model over a distributive and an ideological issue where the legislators are privately informed about their positions on a unidimensional ideological spectrum, and communication takes place before a proposal is offered. Specifically, in our model (1) three legislators bargain over an ideological and a distributive decision; (2) one of the legislators, called the chair, is in charge of formulating the proposal; (3) each legislator other than the chair is privately informed about his own preferences; (4) legislators send costless messages (cheap talk) to the chair before a proposal is offered; (5) majority rule voting determines whether the proposal is implemented. In what we call the "bundled bargaining" game, the chair makes a proposal on the ideological dimension and the distributive dimension simultaneously, and the two dimensions are accepted or rejected together. By contrast, in the "separate bargaining" game, the chair makes one proposal on only the ideological dimension and another on only the distributive dimension, and each proposal is voted on separately. Unlike in the bundled bargaining game, it is possible in this game that a proposal on one dimension passes while the proposal on the other dimension fails to pass.

Since each legislator's ideological position is his private information, the chair is unsure about what is the optimal policy to propose and how much private benefit she has to offer to a legislator to gain his support for a policy decision. But if the legislators' communication is informative,

\footnotetext{
${ }^{1}$ See e.g., http://www.npr.org/templates/story/story.php? storyId=125004701.
} 
then the chair can use their messages to make inferences about the legislators' ideological positions (which we call their types). We show that under some conditions, equilibrium messages from the legislators may convey limited information and dispel some uncertainty about their preferences. In particular, in the bundled bargaining game, a legislator can signal whether he will "cooperate," "compromise" or "fight," depending on how close his position is to the chair's. If either legislator signals his willingness to cooperate, the chair responds by proposing her ideal policy without giving out any private benefit. If both legislators make tough demands by sending the "fight" message, the chair gives up on the ideological issue and extracts the whole surplus in the distributive dimension. Otherwise, she proposes a compromise policy somewhere in between the status quo and her ideal and gives out some private benefit. Only the proposal induced by a "compromise" message may fail to pass in equilibrium whereas the proposals induced by the "cooperate" or "fight" messages always pass.

In a separate bargaining game, the chair is unable to use private benefits to reach compromise on ideological decisions, so she captures the entire surplus on the distributive dimension. But her proposal on the ideological dimension may still depend on the legislators's messages. We show that legislators can signal whether they will "cooperate" or "compromise." Similar to the bundled bargaining game, if either legislator signals willingness to cooperate, the chair responds by proposing her ideal policy. If both legislators send the "compromise" message, then the chair proposes a compromise policy somewhere in between the status quo and her ideal.

Why is it that the legislators may convey their intention to "fight" in the bundled bargaining game whereas they do not do so in the separate bargaining game? To understand this, note that in the bundled bargaining game, reaching an agreement may result in a social surplus. In particular, if the size of the cake to be divided in the distributive dimension is strictly positive, then proposing the status quo ideological policy along with allocating the entire cake to the chair results in a different outcome from the status quo in which all the legislators, including the chair, receive no cake. Indeed, in the special case when the size of the cake to be divided is zero, the proposal made in response to the "fight" message in the bundled bargaining game is just the status quo with no transfers, and an equilibrium in which "cooperate", "compromise" and "fight" messages are sent is outcome equivalent to an equilibrium in which only "cooperate" and "compromise" messages are sent.

Bundled bargaining affords the proposer the flexibility of using private benefits to gain support on policy reforms. As a result, it is always better for the proposer to bundle issues 
under complete information. However, we identify two disadvantages of bundled bargaining under asymmetric information.

One disadvantage of bundling under asymmetric information is the risk of losing the surplus. In our model, when the legislators bargain over the ideological and the distributive issues separately, the agreement on the distributive dimension is always reached, so when the proposal on the ideological dimension fails, no surplus is lost. In contrast, if the two issues are bundled, then failure to reach agreement on the ideological dimension results in the dissipation of the surplus on the distributive dimension.

The second disadvantage of bundling the issues is the informational loss, which arises even when there is no risk of losing the surplus. Specifically, we show that when the size of the surplus is zero, less information may be transmitted in equilibrium when the two dimensions are bundled than when they are separated, in the sense that if an informative equilibrium exists in the bundled bargaining game, then an informative equilibrium exists in the separate bargaining game, but the converse is not true. Intuitively, once side payments become a possibility, it might be too tempting for a legislator to declare that his position is not especially close to the chair's in the hope that the chair will respond with a more attractive deal. This incentive to distort one's message may result in less information transmitted in equilibrium.

This result suggests that it might be better to negotiate over different issues separately rather than to bundle them in one bill, even though bundled bargaining allows the chair to exploit differences in the other legislators' trade-offs between the two dimensions and use private benefits as an instrument to make deals on policy changes that she wants to implement. We show that the overall welfare comparison can go either way. In particular, even when the size of the cake to be divided is zero, informational loss alone can be sufficiently costly that the chair is worse off by bundling the two issues. If we interpret bundling as the possibility of using pork barrel spending to gain support on policy reform, our finding points out another potential harm of pork barrel spending.

In a related paper, Chen and Eraslan (2012) show that bundling is always beneficial when each legislator's position on a unidimensional ideological spectrum is publicly known, but his ideological intensity, that is, the weight he places on the ideological dimension relative to the distributive dimension, is his private information. This is because when the uncertainty is about ideological intensity, both disadvantages of bundled bargaining disappear. First, in the bundled bargaining game, the chair can replicate the optimal proposals in the separate bargaining game 
without the risk of losing the surplus. Second, there is no informational loss from bundling the two issues because no useful information is transmitted in the separate bargaining game where information about ideological intensity is irrelevant.

Before turning to the description of our model, we briefly discuss other related literature. Starting with the seminal work of Baron and Ferejohn (1989), legislative bargaining models have become a staple of political economy and have been used in numerous applications. Like our paper, some papers in the literature include an ideological dimension and a distributive dimension (see, for example, Austen-Smith and Banks (1988), Banks and Duggan (2000), Jackson and Moselle (2002), and Diermeier and Merlo (2004)), but all of these are models of complete information, and except for Jackson and Moselle (2002), do not consider separate bargaining. In Jackson and Moselle (2002), even though the ideological and distributive issues may be considered separately, all equilibria involve proposals and approval of both dimensions simultaneously. Since there is complete information in their model, there is no possibility of informational loss from bundling. Furthermore, agreement is reached immediately in equilibrium, and there is no loss of surplus. Because of the usefulness of the distributive dimension as an instrument for compromise, in equilibrium the ideological issue is not divorced from distributive issue.

Under incomplete information, it is no longer clear that bundled bargaining is always beneficial. For example, Harstad (2007) shows that side payments may be harmful because they increase conflicts of interest and incentives to signal by rejecting offers. This is different from the reason for side payments to be harmful in our model, which is the informational loss. Another related paper is Chakraborty and Harbaugh (2003), which analyzes a bilateral bargaining game over two cakes. One of the players has private information over the relative weights he gives to the cakes and he sends a message to the other player before the other player makes an offer. In Chakraborty and Harbaugh (2003), like in our model, separate bargaining has the advantage that break-down in one dimension does not affect the other. But in their model no information is transmitted in a separate bargaining game whereas an informative equilibrium may exist in the bundled bargaining game. So the adverse effect of bundling on information transmission does not arise in their model. Consequently in their model whether the proposer prefers bundling or separating depends on the importance of information gains relative to the risk of losing both cakes.

Our paper is also related to the literature on cheap talk and bargaining (see, Gilligan and Krehbiel (1987, 1989), Farrell and Gibbons (1989), Matthews (1989), Matthews and Postlewaite 
(1989), and Krishna and Morgan (2001)). Among these papers, the most closely related to ours is Matthews (1989), which models presidential veto threats as cheap talk in a bilateral bargaining game over a unidimensional policy and assumes that the president's position is his private information, but there are a number of important differences between his model and ours. The main difference between his model and our separate bargaining game is that Matthews (1989) considers only bilateral bargaining whereas we consider multi-lateral bargaining. More importantly, Matthews (1989) does not address the question of bundled bargaining versus separate bargaining since the two players in his model bargain over a single ideological decision whereas in our bundled bargaining game, multiple players bargain over a distributive dimension in addition to an ideological dimension.

In the next section we describe our model. We discuss some examples to illustrate the intuition behind our main results in Section 3. We begin the formal analysis in Sections 4 by considering the game with only one legislator (other than the chair) and then move on to the game with two legislators in Section 5. We conclude in Section 6.

\section{Model}

Three legislators play a three-stage game to collectively decide on an outcome that consists of an ideological component and a distributive component. For example, the legislators decide on the level of environmental regulation and the distribution of government spending across districts. Legislator 0 makes the proposal. ${ }^{2}$ From now on we simply refer to legislator 0 as the chair, and use the term legislator to refer to the other two players. Let $z=(y ; x)$ where $y$ is an ideological decision and $x=\left(x_{0}, x_{1}, x_{2}\right)$ is a distributive decision. The set of feasible ideological decisions is $Y=\mathbb{R}$, and the set of feasible distributions is $X=\left\{x \in \mathbb{R}^{3}: \sum_{i=0}^{2} x_{i} \leq c, x_{1} \geq 0, x_{2} \geq 0\right\}$ where $x_{i}$ denotes the private benefit of player $i$ and $c \geq 0$ is the size of the surplus available for division. Note that it is possible that $x_{0}<0$, that is, even when $c=0$, the chair can use transfers to move policy. Although there is no upper bound on the transfers the chair can make, in equilibrium she makes finite transfers under our assumptions on preferences. For $i=1,2$, we say that proposal $(y ; x)$ includes legislator $i$ if $x_{i}>0$ and excludes legislator $i$ if $x_{i}=0 .^{3}$ The

\footnotetext{
${ }^{2}$ We use "she" as the pronoun for the proposer and "he" as the pronoun for legislators 1 and 2.

${ }^{3}$ In the remainder of the paper, when we use $i$ and $j$ to index the legislators, we sometimes omit the quantifiers $i=1,2$ or $j=1,2$. When we refer to both legislator $i$ and legislator $j$, we implicitly assume $j \neq i$.
} 
status quo allocation is $s=(\tilde{y} ; \tilde{x})$ where $\tilde{y} \in Y$ and $\tilde{x}=(0,0,0){ }^{4}$

The payoff of each player $i=0,1,2$ depends on the ideological decision and his/her private benefit. We assume that the players' preferences are separable over the two dimensions. Specifically, player $i$ has a quasi-linear von Neumann-Morgenstern utility function given by

$$
u_{i}\left(z, \theta_{i}, \hat{y}_{i}\right)=x_{i}+\theta_{i} v\left(y, \hat{y}_{i}\right)
$$

where $z=(y ; x)$ is the outcome, $\hat{y}_{i} \in Y$ is player $i$ 's ideal point (ideological position), and $\theta_{i}>0$ is the weight that player $i$ places on his/her payoff from the ideological decision relative to the distributive decision. The marginal rate of substitution, $\left(\partial u_{i} / \partial y\right) /\left(\partial u_{i} / \partial x_{i}\right)=\theta_{i}(\partial v / \partial y)$, measures player $i$ 's preference for ideology relative to private benefit.

Legislator $i=1,2$ privately observes the realization of $\hat{y}_{i}$, called his type, a random variable with distribution function $F_{i}$. We also use $t_{i}$ to denote the type of legislator $i$. The set of possible types of legislator $i$ is $T_{i}=\left[\underline{t}_{i}, \bar{t}_{i}\right] \subset \mathbb{R}_{+}$. We assume that $F_{i}$ is continuous and has full support on $T_{i}$, and the legislators' types are independently distributed. Although $\hat{y}_{i}$ is legislator $i$ 's private information, its distribution and other aspects of his payoff function, including $\theta_{i}$, are common knowledge. In the remainder of the paper, $\theta_{i}$ is fixed and we use $u_{i}\left(z, t_{i}\right)$ to denote legislator $i$ 's payoff from outcome $z$ when his type is $t_{i}$.

For simplicity we assume the chair's preferences are commonly known. Without loss of generality, assume $\hat{y}_{0}<\tilde{y}$, which means that the chair would like to move the policy to the left of the status quo. To simplify notation, we write $u_{0}(z)=x_{0}+\theta_{0} v\left(y, \hat{y}_{0}\right)$ as the chair's payoff from $z$.

We make the following assumptions on $v$ : (1) $v$ is twice differentiable; (2) for any $\hat{y}_{i} \in T_{i}$, $v_{11}\left(y, \hat{y}_{i}\right)<0$ for all $y \in Y$ (which implies that $v$ is concave in $y$ ), and $\hat{y}_{i}$ maximizes $v\left(\cdot, \hat{y}_{i}\right)$; (3) $v_{12}>0$, i.e., $v$ is supermodular in $\left(y, \hat{y}_{i}\right) .^{5}$ Note that the commonly used quadratic-loss function, $v\left(y, \hat{y}_{i}\right)=-\left(y-\hat{y}_{i}\right)^{2}$, satisfies all of these assumptions. To avoid triviality, we assume that $v\left(\tilde{y}, \bar{t}_{i}\right)>v\left(y_{0}, \bar{t}_{i}\right)$ so that some type of legislator $i$ prefers the status quo policy $\tilde{y}$ to the chair's ideal $\hat{y}_{0}$.

\footnotetext{
${ }^{4}$ The assumption that $\tilde{x}=(0,0,0)$, together with the definition of $X$, implies that the total surplus for reaching an agreement is non-negative, legislator 1's and legislator 2's status quo private benefits are the same, and the chair's proposal cannot offer private benefits lower than his status quo to either legislator 1 or 2 .

${ }^{5}$ In Matthews (1989), only single-crossing property is needed to guarantee that a more rightist type prefers a more rightist policy. Once we allow a distributive dimension, supermodularity is needed to guarantee this (Lemma 1).
} 
The bargaining game has three stages. In stage one, each legislator $i=1,2$ observes his type $t_{i}$ and sends a message simultaneously to the chair. ${ }^{6}$ In stage two, the chair observes the messages and makes a proposal in $Y \times X$. In stage three, the players vote on the proposal under majority rule. Without loss of generality we assume that the chair votes for the proposal. So a proposal passes if at least one of legislators 1 and 2 votes for it. Otherwise, the status quo $s$ prevails. (Here we describe the bundled bargaining game. In the separate bargaining game, in stage two, the chair observes the messages and makes one proposal in $Y$ and another proposal in $X$, and in stage three, the players vote on each of the two proposals under majority rule. We omit a full description of the extensive form and the equilibrium conditions in the separate bargaining game since they are analogous to the ones in the bundled bargaining game.)

The set of allowed messages for legislator $i$, denoted by $M_{i}$, is a finite set that has more than two elements. The messages have no literal meanings (we discuss their equilibrium meanings later); they are also "cheap talk" since they do not affect the players' payoffs directly. The assumption that $M_{i}$ is finite rules out the possibility of separating equilibria, but we show that separating equilibria are not possible even if $M_{i}$ 's are infinite.

A strategy for legislator $i$ consists of a message rule in the first stage and an acceptance rule in the third stage. A message rule $\mu_{i}: T_{i} \rightarrow M_{i}$ specifies the message legislator $i$ sends as a function of his type. An acceptance rule $\gamma_{i}: Y \times X \times T_{i} \rightarrow\{0,1\}$ specifies how legislator $i$ votes as a function of his type: type $t_{i}$ accepts a proposal $z$ if $\gamma_{i}\left(z, t_{i}\right)=1$ and rejects it if $\gamma_{i}\left(z, t_{i}\right)=0 .{ }^{7}$ The strategy set for legislator $i$ consists of pairs of measurable functions $\left(\mu_{i}, \gamma_{i}\right)$ satisfying these properties. The chair's strategy set consists of all proposal rules $\pi: M_{1} \times M_{2} \rightarrow Y \times X$ where $\pi\left(m_{1}, m_{2}\right)$ is the proposal she offers when receiving $\left(m_{1}, m_{2}\right)$.

Fix a strategy profile $(\mu, \gamma, \pi)$. Say that a message profile $m=\left(m_{1}, m_{2}\right)$ induces proposal $z$ if $\pi(m)=z$. Proposal $z$ is elicited by type $t_{i}$ if it is induced by $m$ with $m_{i}=\mu_{i}\left(t_{i}\right)$ and $\left\{t_{j}: \mu_{j}\left(t_{j}\right)=m_{j}\right\} \neq \emptyset$. If $z$ is induced by $m$, then, legislator $i$ is pivotal with respect to $z$ if $\gamma_{j}\left(z, t_{j}\right)=0$ for all $t_{j}$ such that $\mu_{j}\left(t_{j}\right)=m_{j}$ and non-pivotal with respect to $z$ otherwise.

To define an equilibrium for this game, let $\beta_{i}\left(z \mid m_{i}\right)$ denote the chair's probabilistic belief

\footnotetext{
${ }^{6}$ The message can be either private or public. Since condition (E1) in the upcoming definition of equilibrium requires that each legislator votes for a proposal if and only if he prefers that proposal to the status quo, our results do not depend on whether the messages are private or public.

${ }^{7}$ Technically a legislator's acceptance rule can depend on his message. However, condition (E1) in the upcoming definition of equilibrium says that legislator $i$ accepts a proposal if and only if he prefers it to the status quo, independent of the message he sent. As such, we suppress the dependence of $\gamma_{i}$ on $m_{i}$.
} 
that legislator $i$ votes to accept proposal $z$ conditional on sending message $m_{i}$. Given the strategy $\left(\mu_{i}, \gamma_{i}\right)$ of legislator $i, \beta_{i}$ is derived by Bayes' rule whenever possible. That is,

$$
\beta_{i}\left(z \mid m_{i}\right)=\int_{\left\{t_{i}: \mu_{i}\left(t_{i}\right)=m_{i}\right\}} \gamma_{i}\left(z, t_{i}\right) d F_{i}\left(t_{i}\right) / \int_{\left\{t_{i}: \mu_{i}\left(t_{i}\right)=m_{i}\right\}} d F_{i}\left(t_{i}\right)
$$

if $\int_{\left\{t_{i}: \mu_{i}\left(t_{i}\right)=m_{i}\right\}} d F_{i}\left(t_{i}\right)>0$.

Definition. An equilibrium is a strategy profile $(\mu, \gamma, \pi)$ such that the following conditions hold for all $i \neq 0, t_{i} \in T_{i}, y \in Y, x \in X$ and $m \in M_{1} \times M_{2}$ :

(E1) $\gamma_{i}\left(z, t_{i}\right)=1$ if $u_{i}\left(z, t_{i}\right) \geq u_{i}\left(s, t_{i}\right)$, and $\gamma_{i}\left(z, t_{i}\right)=0$ otherwise.

(E2) $\pi(m) \in \arg \max _{z^{\prime} \in Y \times X} u_{0}\left(z^{\prime}\right) \beta\left(z^{\prime} \mid m\right)+u_{0}(s)\left(1-\beta\left(z^{\prime} \mid m\right)\right)$, where

$$
\beta\left(z^{\prime} \mid m\right)=1-\left(1-\beta_{1}\left(z^{\prime} \mid m_{1}\right)\right)\left(1-\beta_{2}\left(z^{\prime} \mid m_{2}\right)\right)
$$

is the conditional probability that $z^{\prime}$ is accepted.

(E3) If $\mu_{i}\left(t_{i}\right)=m_{i}$, then $m_{i} \in \arg \max _{m_{i}^{\prime}} V_{i}\left(m_{i}^{\prime}, t_{i}\right)$ where

$$
\begin{aligned}
V_{i}\left(m_{i}^{\prime}, t_{i}\right)= & \int_{T_{j}}\left[\gamma_{j}\left(\pi\left(m_{i}^{\prime}, \mu_{j}\left(t_{j}\right)\right), t_{j}\right) u_{i}\left(\pi\left(m_{i}^{\prime}, \mu_{j}\left(t_{j}\right)\right), t_{i}\right)\right. \\
& \left.+\left(1-\gamma_{j}\left(\pi\left(m_{i}^{\prime}, \mu_{j}\left(t_{j}\right)\right), t_{j}\right)\right) \max \left\{u_{i}\left(\pi\left(m_{i}^{\prime}, \mu_{j}\left(t_{j}\right)\right), t_{i}\right), u_{i}\left(s, t_{i}\right)\right\}\right] d F_{j}\left(t_{j}\right) .
\end{aligned}
$$

Condition (E1) requires each legislator to accept a proposal if and only if he prefers it to the status quo. ${ }^{8}$ Condition (E2) requires that equilibrium proposals maximize the chair's payoff and that her belief is consistent with Bayes' rule. Condition (E3) requires that a legislator elicits only his most preferred distribution of proposals, incorporating the acceptance rules.

For expositional simplicity, from now on we assume that in equilibrium, if $\beta(z \mid m)=0$, then $\pi(m) \neq z$, i.e., if a proposal is rejected with probability 1 , then the chair does not propose it. ${ }^{9}$

Say that a proposal $z$ is elicited in the equilibrium $(\mu, \gamma, \pi)$ if there exists $\left(t_{1}, t_{2}\right) \in T_{1} \times T_{2}$ such that $z=\pi\left(\mu_{1}\left(t_{1}\right), \mu_{2}\left(t_{2}\right)\right)$. For any fixed strategy profile $(\mu, \gamma, \pi)$, the outcome for $\left(t_{1}, t_{2}\right)$ is

\footnotetext{
${ }^{8}$ Condition (E1) strengthens the requirement of Perfect Bayesian Equilibrium (PBE) and is the only difference between our equilibrium solution concept and PBE. In particular, (E1) rules out the (weakly dominated) acceptance rule of accepting any proposal because a legislator expects that the other legislator accepts any proposal.

${ }^{9}$ This is not a restrictive assumption if $c>0$ because the chair strictly prefers the proposal $(\tilde{y} ; c, 0,0)$ (which is accepted with probability 1 ) to the status quo, so $z$ is not a best response. If $c=0$, however, it is possible that $z$ is a best response, but not a unique one (for example, $s$ is another best response).
} 
$\pi\left(\mu_{1}\left(t_{1}\right), \mu_{2}\left(t_{2}\right)\right)$ if at least one of legislators 1 and 2 accepts $\pi\left(\mu_{1}\left(t_{1}\right), \mu_{2}\left(t_{2}\right)\right)$, and the outcome for $\left(t_{1}, t_{2}\right)$ is $s$ if both legislators 1 and 2 reject $\pi\left(\mu_{1}\left(t_{1}\right), \mu_{2}\left(t_{2}\right)\right)$. Say that two equilibria are outcome equivalent if they generate the same outcome for almost all type profiles.

A babbling equilibrium is an equilibrium $(\mu, \gamma, \pi)$ in which $\mu_{i}\left(t_{i}\right)=\mu_{i}\left(t_{i}^{\prime}\right)$ for all $t_{i}, t_{i}^{\prime} \in T_{i}$, $i=1,2$, i.e., all types of legislator $i$ send the same message, and $\pi(m)=\pi\left(m^{\prime}\right)$ for all $m, m^{\prime} \in M_{1} \times M_{2}$, i.e., the chair responds to all message profiles with the same proposal. As is standard in cheap-talk models, a babbling equilibrium always exists.

\section{$3 \quad$ Examples}

Before we conduct the formal analysis, we discuss some simple examples to illustrate the advantages and disadvantages of bundled bargaining compared to separate bargaining. For simplicity, the examples in this section involves only one legislator (legislator 1) other than the chair and a proposal needs legislator 1's vote to pass. As we show in Section 5, the same logic holds when there are two legislators other than the chair.

We start by showing that in the benchmark case of complete information, bundled bargaining is always beneficial to the chair. One useful piece of notation is $e\left(\hat{y}_{1}\right)$, the policy closest to the chair's ideal such that legislator 1 whose ideal is $\hat{y}_{1}$ is willing to accept without any transfer. Recall that $\hat{y}_{0}<\tilde{y}$ so that the chair wants to move the policy to the left of the status quo. Formally, $e\left(\hat{y}_{1}\right)=\min \left\{y \geq \hat{y}_{0}: v\left(y, \hat{y}_{1}\right) \geq v\left(\tilde{y}, \hat{y}_{1}\right)\right\}$.

Example 1 (Complete information: bundled bargaining is better for the chair). Suppose $\tilde{y}=0, \hat{y}_{0}=-1, u_{i}\left(z, \hat{y}_{i}\right)=x_{i}-\left(y-\hat{y}_{i}\right)^{2}$ for $i=0,1$.

In the separate bargaining game, the chair proposes to give no transfer to legislator 1 on the distributive dimension and proposes $e\left(\hat{y}_{1}\right)$ on the ideological dimension, and both proposals pass. To find $e\left(\hat{y}_{1}\right)$, note that legislator 1 with an ideal of $\hat{y}_{1}$ is indifferent between the status quo policy $\tilde{y}=0$ and the policy $2 \hat{y}_{1}$. In addition, $e\left(\hat{y}_{1}\right)$ is to the right of $\hat{y}_{0}$ and to the left of $\tilde{y}$. Hence, $e\left(\hat{y}_{1}\right)=\min \left\{0, \max \left\{2 \hat{y}_{1},-1\right\}\right\}$ in this example.

Now consider the bundled bargaining game. Under the quadratic-loss utility function, straightforward calculation shows that the optimal proposal, as a function of legislator 1's ideal $\hat{y}_{1}$, must satisfy

$$
y\left(\hat{y}_{1}\right)=\max \left\{\hat{y}_{0}, \min \left\{\frac{\theta_{0} \hat{y}_{0}+\theta_{1} \hat{y}_{1}}{\theta_{0}+\theta_{1}}, e\left(\hat{y}_{1}\right)\right\}\right\}=\max \left\{-1, \min \left\{\frac{-1+\hat{y}_{1}}{2}, e\left(\hat{y}_{1}\right)\right\}\right\},
$$




$$
x_{1}\left(\hat{y}_{1}\right)=\theta_{1}\left[v\left(\tilde{y}, \hat{y}_{1}\right)-v\left(y\left(\hat{y}_{1}\right), \hat{y}_{1}\right)\right]=\left[y\left(\hat{y}_{1}\right)-2 \hat{y}_{1}\right] y\left(\hat{y}_{1}\right)
$$

Since the chair can always propose $\left(e\left(\hat{y}_{1}\right) ; c, 0\right)$ in the bundled bargaining game and have it accepted, the chair is clearly better off in the bundled bargaining game than in the separate bargaining game. When $y\left(\hat{y}_{1}\right) \neq e\left(\hat{y}_{1}\right)$, the chair's optimal proposal under bundled bargaining is not $\left(e\left(\hat{y}_{1}\right) ; c, 0\right)$ and she is strictly better off in the bundled bargaining game. This happens when $\frac{-1+\hat{y}_{1}}{2}<e\left(\hat{y}_{1}\right)$ and $\hat{y}_{0}<e\left(\hat{y}_{1}\right)$, which holds when $\hat{y}_{1}$ is in an intermediate range, as Figure 1 illustrates. Intuitively, if legislator 1's position is sufficiently far from the chair's, then it is too costly to move the policy closer to the chair's ideal by compensating legislator 1 on the distributive dimension; and if legislator 1's position is sufficiently close to the chair's, then the chair can achieve a policy reform close enough to her ideal without giving legislator 1 any transfer, again making the no-transfer proposal $\left(e\left(\hat{y}_{1}\right) ; c, 0\right)$ optimal. So the flexibility of trading private benefits for policy compromises provided by bundled bargaining is especially valuable when legislator 1 holds a position neither too close nor too far from the chair's.

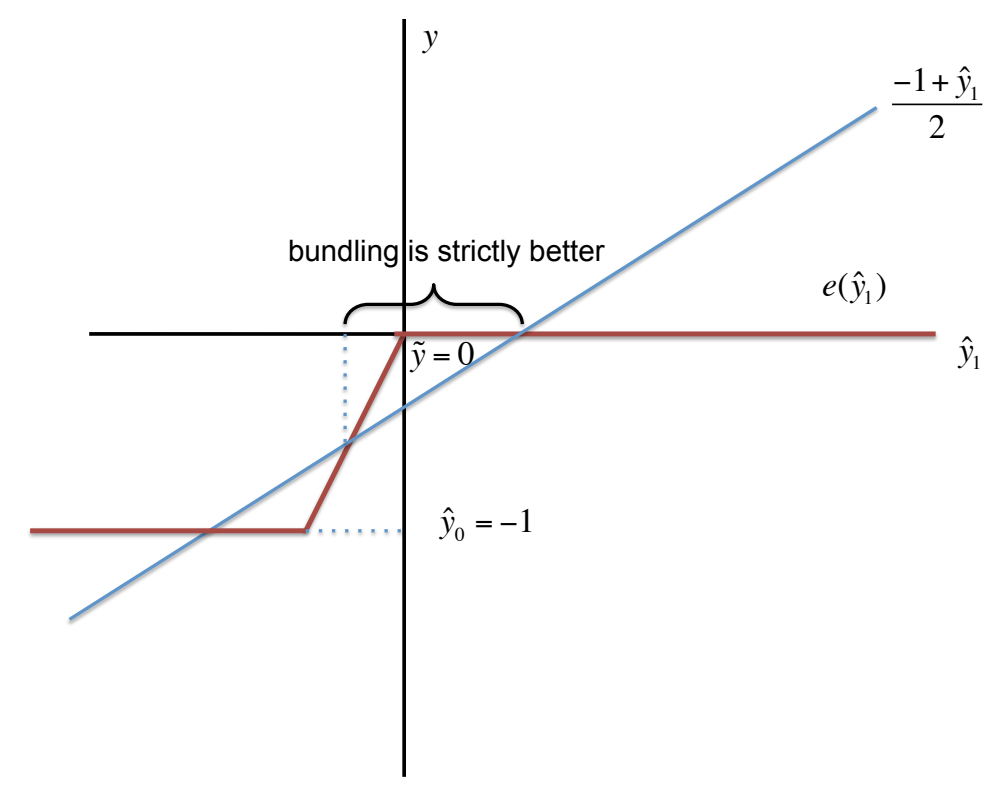

Figure 1: Complete information - the chair benefits from bundled bargaining

Although the chair benefits from bundled bargaining under complete information because of the flexibility afforded by bundling the issues, two other forces come into effect under asymmetric information, both of which make bundling less attractive. The first is the risk of losing the surplus under bundled bargaining since a proposal may fail to pass in equilibrium under 
asymmetric information. The second, and the more subtle, force is the informational loss that may result from bundled bargaining. The following examples illustrate these two disadvantages of bundled bargaining.

Example 2 (Asymmetric information: risk of losing the surplus from bundled bargaining). Suppose $\tilde{y}=0, \hat{y}_{0}=-1, c=1, u_{i}\left(z, \hat{y}_{i}\right)=x_{i}-\left(y-\hat{y}_{i}\right)^{2}$ for $i=0,1$ and $\hat{y}_{1}$ (equivalently, $\left.t_{1}\right)$ is uniformly distributed on $[-0.4,1]$.

Straightforward calculation shows that no information is transmitted in the unique equilibrium outcome in either the separate bargaining game or the bundled bargaining game.

In the separate bargaining game, the chair proposes $y=-0.18$ on the ideological dimension and legislator 1 accepts $y$ if and only if $t_{1} \leq-0.36$ in equilibrium. ${ }^{10}$ The chair's expected equilibrium payoff on the ideological dimension is -0.91 . On the distributive dimension, the chair proposes $\left(x_{0}, x_{1}\right)=(c, 0)=(1,0)$, and this proposal is accepted by all types of legislator 1 . Overall, the expected equilibrium payoff for the chair is equal to 0.09 in the separate bargaining game.

In the uninformative equilibrium of the bundled bargaining game, the chair's optimal proposal is equal to $(\tilde{y} ; c, 0)=(0 ; 1,0)$ and it is accepted by all types of legislator 1 . The expected equilibrium payoff for the chair is equal to 0 in the bundled bargaining game, lower than her equilibrium payoff in the separate bargaining game.

Intuitively, since the surplus $c$ dissipates when a proposal fails to pass in the bundled bargaining game, and the chair faces high uncertainty regarding legislator 1's ideological position, she "plays it safe" by making a proposal that is accepted by all types of legislator 1 . In this example, this proposal involves the status quo policy and no private benefit for legislator 1 . In the separate bargaining game, on the other hand, the surplus does not dissipate even if agreement breaks down on the ideological dimension. This makes it optimal for the chair to propose a compromise policy $y=-0.18$ instead of maintaining the status quo policy. Although this proposal is rejected with positive probability by legislator 1 (when $t_{1}>-0.36$ ), the chair still receives the surplus $c$ since the distributive dimension is shielded from the failure of agreement on the ideological dimension.

Another, perhaps less obvious, disadvantage of bundling is the informational loss that may result from bargaining the two dimensions together. This matters even if there is no risk of

\footnotetext{
${ }^{10}$ The numbers in our examples are rounded to the second decimal.
} 
"losing the cake." To illustrate, suppose $c=0$, so that failure to reach agreement does not result in the dissipation of private benefits.

Example 3 (Asymmetric information: informational loss from bundled bargaining). Suppose $\tilde{y}=0, \hat{y}_{0}=-1, c=0, u_{i}\left(z, \hat{y}_{i}\right)=x_{i}-\theta_{i}\left(y-\hat{y}_{i}\right)^{2}$ for $i=0,1$ with $\theta_{1}=1$. Suppose also that $\hat{y}_{1}$ (equivalently, $t_{1}$ ) is uniformly distributed on $[-1,1]$.

Consider first the separate bargaining game (which is equivalent to the game in which the chair is not allowed to make any transfers). Independent of the value of $\theta_{0}$, the following informative equilibrium exists. Legislator 1 plays the following message rule: $\mu_{1}\left(t_{1}\right)=m_{1}^{1}$ if $t_{1} \in[-1,-0.57]$ and $\mu_{2}\left(t_{2}\right)=m_{1}^{2}$ if $t_{1} \in[-0.57,1]$. The chair responds to the message $m_{1}^{1}$ by proposing his ideal policy $\tilde{y}_{0}=-1$ and it is accepted by all types in $[-1,-0.57]$. The chair responds to the message $m_{1}^{2}$ by proposing a compromise policy $y=-0.14$, and it is accepted by legislator 1 if $t_{1} \in[-0.57,-0.07)$ and rejected by legislator 1 if $t_{1} \in(-0.07,1]$. The chair's expected payoff in the size-two equilibrium in the separate bargaining game is equal to $-0.45 \theta_{0}$.

Now consider the bundled bargaining game, that is, the chair can make transfers to legislator 1 in order to reach agreement on ideological decisions. If $\theta_{0}$ is sufficiently high, i.e., the chair is intensely ideological, then informative equilibria fail to exist. For example, suppose $\theta_{0}=4$. Then no informative equilibrium exists in the bundled bargaining game. To see why, suppose that legislator 1 uses the same message rule as in the separate bargaining game: $\mu_{1}\left(t_{1}\right)=m_{1}^{1}$ if $t_{1} \in[-1,-0.57]$ and $\mu_{2}\left(t_{2}\right)=m_{1}^{2}$ if $t_{1} \in[-0.57,1]$. Then, if the chair receives $m_{1}^{1}$, she responds by proposing $y=\tilde{y}_{0}$ and making no transfer. If the chair receives $m_{1}^{2}$, she responds by proposing $y=-0.6$ and making a transfer of 1.56 to legislator 1 . But given the chair's responses, all types of legislator 1 would send $m_{1}^{2}$, and therefore this is not an equilibrium. Intuitively, because legislator 1 is tempted to pose a tough stance in order to extract a better deal from the chair, it is impossible for his messages to be informative in equilibrium.

What are the welfare implications of the informational loss from bundled bargaining? Although the flexibility afforded by transfers makes the chair better off when the information she has is fixed, the informational loss from bundling can be sufficiently high that the chair would be better off if she can commit not to use transfers. Indeed, in the above example where $\theta_{0}=4$, the chair's equilibrium payoff in the bundled bargaining game is equal to -2.2 , lower than her expected payoff in the informative equilibrium in the separate bargaining game $(-1.8)$. Of course, if the chair places a sufficiently high weight on the ideological dimension relative to the 
distributive dimension, then the gain from using transfers to make deals on ideological policies outweighs the informational loss from bundled bargaining. To see this, consider the limit case as $\theta_{0}$ goes to $\infty$, that is, the chair cares about only the ideological decision, not the distributive decision. In the bundled bargaining game, the chair would optimally propose $y=\hat{y}_{0}$ and make a transfer large enough that all types of legislator 1 accepts her proposal. This is clearly better than what the chair can achieve without using transfers.

In the rest of the paper, we characterize equilibria and generalize these examples. In particular, in Proposition 3, we show that more information is transmitted in the separate bargaining game in the sense that if an informative equilibrium exists in the bundled bargaining game, then it exists in the separate bargaining game, but the converse is not true. We also show that the results are robust when there are two senders.

\section{One sender}

We start by analyzing a simple game with only one sender and then analyze the game with two senders. The modifications of strategies and equilibria are straightforward and omitted. To characterize equilibria, we establish the following lemma, which follows from supermodularity of $v$ in $\left(y, \hat{y}_{i}\right)$. It says that between two proposals with different ideological components, if a type prefers the proposal with a more rightist (leftist) policy, then any type to the right (left) also prefers the proposal with the more rightist (leftist) policy. (All proofs are in the appendix.)

Lemma 1. Consider $z=(y ; x)$ and $z^{\prime}=\left(y^{\prime} ; x^{\prime}\right)$ with $y^{\prime}>y$. (i) If $u_{i}\left(z^{\prime}, t_{i}\right) \geq u_{i}\left(z, t_{i}\right)$, then $u_{i}\left(z^{\prime}, t_{i}^{\prime}\right)>u_{i}\left(z, t_{i}^{\prime}\right)$ for $t_{i}^{\prime}>t_{i}$. (ii) If $u_{i}\left(z^{\prime}, t_{i}\right) \leq u_{i}\left(z, t_{i}\right)$, then $u_{i}\left(z^{\prime}, t_{i}^{\prime}\right)<u_{i}\left(z, t_{i}^{\prime}\right)$ for $t_{i}^{\prime}<t_{i}$.

When there is only one sender and he is privately informed about his ideological position, our model is similar to that in Matthews (1989). The difference is that the players in our model bargain over a distributive dimension as well as an ideological dimension whereas in Matthews (1989) they bargain over only an ideological dimension.

Let the size of an equilibrium be the number of proposals elicited in it. Matthews (Proposition 2) shows that an equilibrium has at most size two. We have a similar result which says that an equilibrium has at most size three. (Abusing notation, in our discussion of the onesender model, we use $x$ to denote the division of surplus between the chair and legislator 1 . So $z=(y ; x)$ where $x \in X=\left\{x \in \mathbb{R}^{2}: x_{0}+x_{1} \leq c, x_{1} \geq 0\right\}$.) 
Proposition 1. (i) An equilibrium has at most size three. (ii) If $z=(y ; x)$ is elicited in equilibrium, then $y \leq \tilde{y}$. If $y=\tilde{y}$, then $x=(c, 0)$. (iii) If $z=(y ; x)$ and $z^{\prime}=\left(y^{\prime} ; x^{\prime}\right)$ are elicited in equilibrium with $y<y^{\prime}<\tilde{y}$, then $z=\left(\hat{y}_{0} ; c, 0\right)$.

To understand Proposition 1, note first that the chair never proposes a policy to the right of $\tilde{y}$ because $(\tilde{y} ; c, 0)$ is accepted with probability 1 (part (ii)). The key step in establishing that an equilibrium has at most size three is part (iii), which says that at most one proposal elicited in equilibrium involves a compromise policy $y \in\left(\hat{y}_{0}, \tilde{y}\right)$. To see why this holds, suppose $z=(y ; x)$ and $z^{\prime}=\left(y^{\prime} ; x^{\prime}\right)$ are elicited in equilibrium, with $y, y^{\prime} \in\left(\hat{y}_{0}, \tilde{y}\right)$ and $y<y^{\prime}$. Then some types of legislator 1 prefer $z$ to $z^{\prime}$, some types prefer $z^{\prime}$ to $z$ and a certain type $\tilde{t}_{1}$ is indifferent between $z^{\prime}$ and $z$ and strictly prefer $z$ and $z^{\prime}$ to the status quo $s$. Lemma 1 implies that more rightist types prefer more rightist policies. It follows that any type to the left of $\tilde{t}_{1}$ strictly prefers $z$ to $s$ and no type to the right of $\tilde{t}_{1}$ elicits $z$ and accepts it. Hence, when the chair receives the message to which she is supposed to respond by proposing $z$, she knows that legislator 1's type is such that he strictly prefers $z$ to $s$. If $z \neq\left(\hat{y}_{0} ; c, 0\right)$ (the proposal that gives the chair the highest possible payoff), there exists another proposal that makes the chair strictly better off if she proposes it instead of $z$. Hence $z=\left(\hat{y}_{0} ; c, 0\right)$ and it follows that an equilibrium has at most size three.

The intuition for our Proposition 1 is similar to the intuition for Proposition 2 in Matthews (1989). But why is it that a size-three equilibrium may exist in our model whereas in Matthews (1989), an equilibrium has at most size two? To clarify the difference, note that in our model, reaching an agreement may result in a social surplus $c$. In particular, if $c>0$, proposing $(\tilde{y} ; c, 0)$ and having it passed results in a different outcome from the status quo, $(\tilde{y} ; 0,0)$. Indeed, in the special case when $c=0,(\tilde{y} ; c, 0)$ is the same as the status quo and a size-three equilibrium is outcome equivalent to a size-two equilibrium, similar to Matthews (1989). ${ }^{11}$ Note, however, that even when $c=0$, our model is still different from Matthews (1989) since the chair can use transfers. ${ }^{12}$

\footnotetext{
${ }^{11}$ To see this, start from a size-three equilibrium in which types $t_{1}<\tau_{1}^{*}$ elicit $\left(\hat{y}_{0} ; c, 0\right)$, types $t_{1} \in\left(\tau_{1}^{*}, \tau_{1}^{* *}\right)$ elicit $(y ; x)$ with $y \in\left(\hat{y}_{0}, \tilde{y}\right)$ and types $t_{1}>\tau_{1}^{* *}$ elicit $(\tilde{y} ; c, 0)$. Now construct a size-two equilibrium that is the same as the size-three equilibrium except that instead of eliciting $(\tilde{y} ; c, 0)$, types $t_{1}>\tau_{1}^{* *}$ elicit $(y ; x)$ and reject it. This results in the same outcome as the size-three equilibrium when $c=0$.

${ }^{12}$ For example, suppose $\tilde{y}=0, \hat{y}_{0}=-1, c=0, u_{i}\left(z, \hat{y}_{i}\right)=x_{i}-\left(y-\hat{y}_{i}\right)^{2}$ for $i=0,1$ and $\hat{y}_{1}$ is uniformly distributed on $[-2,2]$. If transfers are allowed, as in our model, then there exists an equilibrium in which legislator 1 sends $m_{1}^{1}$ if $\hat{y}_{1} \leq 1 / 5$ and $m_{1}^{2}$ if $\hat{y}_{1}>1 / 5$ and the chair responds to $m_{1}^{1}$ by $\left(-\frac{2}{5} ;-\frac{8}{25}, \frac{8}{25}\right)$ and to $m_{1}^{2}$ by $(0 ; 0,0)$.
} 
Next, we characterize equilibria of different sizes and provide existence conditions. We omit the characterization of size-one equilibria because it is similar to the uncertain ideological intensity case discussed earlier.

\subsection{Size-one equilibria}

Any size-one equilibrium is outcome equivalent to a babbling equilibrium, so we focus on babbling equilibrium here. Recall that in a babbling equilibrium, $\mu_{1}\left(t_{1}\right)=\mu_{1}\left(t_{1}^{\prime}\right)$ for all $t_{1}, t_{1}^{\prime} \in T_{1}$ and $\pi(m)=z^{\prime}$ for all $m \in M_{1}$.

To find $z^{\prime}$, first note that the chair would never offer any $z=(y ; x)$ with $y>\tilde{y}$. Next, by Lemma 1 , for any $z=(y ; x)$ with $y \leq \tilde{y}$ if $u_{1}\left(z, \bar{t}_{1}\right) \geq u_{1}\left(s, \bar{t}_{1}\right)$, then $u_{1}\left(z, t_{1}\right) \geq u_{1}\left(s, t_{1}\right)$ for all $t_{1}<\bar{y}_{1}$ and therefore $z$ is always accepted; if $u_{1}\left(z, \underline{t}_{1}\right)<u_{1}\left(s, \underline{t}_{1}\right)$, then $u_{1}\left(z, t_{1}\right)<u_{1}\left(s, t_{1}\right)$ for all $t_{1}>\underline{t}_{1}$ and therefore $z$ is always rejected; if $u_{1}\left(z, \bar{t}_{1}\right)<u_{1}\left(s, \bar{t}_{1}\right)$ and $u_{1}\left(z, \underline{t}_{1}\right) \geq u_{1}\left(s, \underline{t}_{1}\right)$, then there exists a $t_{1} \in Y_{1}$ such that $u_{1}\left(z, t_{1}\right)=u_{1}\left(s, t_{1}\right)$ and the proposal is accepted with probability $F_{1}\left(t_{1}\right)$.

For any $z=(y ; x)$ with $y \leq \tilde{y}$, let $\tau_{1}(z)$ denote the rightmost type who is willing to accept $z$ if $z$ is accepted with positive probability and set $\tau_{1}(z)$ to $\underline{t}_{1}$ if $z$ is accepted with probability 0. Formally

$$
\tau_{1}(z)=\left\{\begin{array}{cc}
\max \left\{t_{1} \in T_{1}: u_{1}\left(z, t_{1}\right) \geq u_{1}\left(s, t_{1}\right)\right\} & \text { if } u_{1}\left(z, \underline{t}_{1}\right) \geq u_{1}\left(s, \underline{t}_{1}\right), \\
\underline{t}_{1} & \text { otherwise }
\end{array}\right.
$$

For $z^{\prime}$ to be the proposal elicited in a babbling equilibrium, it must satisfy

$$
z^{\prime} \in \underset{z}{\arg \max } u_{0}(z) F_{1}\left(\tau_{1}(z)\right)+u_{0}(s)\left[1-F_{1}\left(\tau_{1}(z)\right)\right]
$$

Equivalently, we can formulate the chair's problem as choosing the rightmost type who is willing to accept her proposal. Let $t_{1}^{\prime}$ be the rightmost type willing to accept $z^{\prime}$. Then

$$
t_{1}^{\prime} \in \underset{t_{1}}{\arg \max } U_{0}\left(t_{1}\right) F_{1}\left(t_{1}\right)+u_{0}(s)\left(1-F_{1}\left(t_{1}\right)\right),
$$

where

$$
U_{0}\left(t_{1}\right)=\max _{z} u_{0}(z)=\left(c-x_{1}\right)+\theta_{0} v\left(y, \hat{y}_{0}\right)
$$

subject to $x_{1} \geq 0$ and $x_{1}+\theta_{1} v\left(y, t_{1}\right) \geq \theta_{1} v\left(\tilde{y}, t_{1}\right)$. That is, $U_{0}\left(t_{1}\right)$ is the value function when the chair negotiates with a single legislator whose ideal point is $t_{1}$. A sufficient condition for $t_{1}^{\prime}$ to be unique is that the objective function is concave or that it is strictly increasing.

Clearly, this cannot happen if transfers are not allowed. 


\subsection{Size-two equilibria}

By parts (ii) and (iii) of Proposition 1, we can categorize size-two equilibria in terms of the set of elicited proposals and there are two kinds of size-two equilibria.

(1) Consider a size-two equilibrium in which the elicited proposals are $\left(\hat{y}_{0} ; c, 0\right)$ and $(y ; x)$ with $y \in\left(\hat{y}_{0}, \tilde{y}\right]$. (This includes the possibility that $y=\tilde{y}$, in which case $x=(c, 0)$.) Call this a "cooperate-or-compromise" equilibrium.

In this equilibrium, there exists a type $\tau_{1}^{*}$ indifferent between $\left(\hat{y}_{0} ; c, 0\right)$ and $(y ; x)$. By Lemma 1 , any type $t_{1}<\tau_{1}^{*}$ strictly prefers $\left(\hat{y}_{0} ; c, 0\right)$ to $(y ; x)$ and therefore elicits $\left(\hat{y}_{0} ; c, 0\right)$ and accepts it. Similarly, any type $t_{1}>\tau_{1}^{*}$ strictly prefers $(y ; x)$ to $\left(\hat{y}_{0} ; c, 0\right)$. If $(y ; x)=(\tilde{y} ; c, 0)$, then any type $t_{1}>\tau_{1}^{*}$ elicits $(y ; x)$ and accepts it in this equilibrium. If $y<\tilde{y}$, then there exists a $\tau_{1}^{* *} \leq \bar{t}_{1}$ such that type $\tau_{1}^{* *}$ is indifferent between $(y ; x)$ and the status quo $s .{ }^{13}$ Types $t_{1} \in\left(\tau_{1}^{*}, \tau_{1}^{* *}\right]$ elicit $(y ; x)$ and accept it. If $\tau_{1}^{* *}<\bar{t}_{1}$, then for any type $t_{1} \in\left(\tau_{1}^{* *}, \bar{t}_{1}\right]$, he prefers $s$ to both $\left(\hat{y}_{0} ; c, 0\right)$ and $(y ; x)$ and would reject either proposal when it is elicited. It seems implausible, however, that a legislator would elicit a proposal that is not his most preferred, even if he were planning a rejection. If there were any probability that he might not carry out a planned rejection, then the legislator should safely elicit only his most preferred elicitable proposal. This implies that types $t_{1} \in\left(\tau_{1}^{* *}, \bar{t}_{1}\right]$ should elicit $(y ; x)$ and reject it. And it follows that the types who elicit the same proposal forms an interval. (In the rest of our discussion of the one-sender game, we assume that in equilibrium, a legislator elicits only his most preferred proposal.)

Let $h\left(t_{1}^{\prime}, t_{1}^{\prime \prime}\right)$ be the set of feasible proposals that are optimal for the chair when she knows that legislator 1 's type is in the interval $\left[t_{1}^{\prime}, t_{1}^{\prime \prime}\right]$. A "cooperate-or-compromise" equilibrium exists if and only if $u_{1}\left(\left(\hat{y}_{0} ; c, 0\right), t_{1}^{*}\right)=u_{1}\left(z, t_{1}^{*}\right)$ for some type $t_{1}^{*} \in T_{1}$ such that $z \in h\left(t_{1}^{*}, \bar{t}_{1}\right)$ and $z \neq\left(\hat{y}_{0} ; c, 0\right){ }^{14}$

(2) Consider a size-two equilibrium in which the elicited proposals are $(y ; x)$ with $y \in\left[\hat{y}_{0}, \tilde{y}\right)$ and $(\tilde{y} ; c, 0)$. Call this a "compromise-or-fight" equilibrium.

In this equilibrium, there exists a type $\tau_{1}^{*}$ indifferent between $(y ; x)$ and $(\tilde{y} ; c, 0)$. Any type $t_{1}<\tau_{1}^{*}$ strictly prefers $(y ; x)$ to $(\tilde{y} ; c, 0)$ and therefore elicits $(y ; x)$ and accepts it. Any type $t_{1}>\tau_{1}^{*}$ strictly prefers $(\tilde{y} ; c, 0)$ to $(y ; x)$ and therefore elicits $(\tilde{y} ; c, 0)$ and accepts it. A "compromise-or-fight" equilibrium exists if and only if there is some type $t_{1}^{*} \in T_{1}$ such that

\footnotetext{
${ }^{13}$ Such a type exists, since otherwise the proposal $(y ; x)$ is not optimal for the chair.

${ }^{14}$ To see why the conditions are sufficient, let $\mu_{1}\left(t_{1}\right)=m_{1}^{1}$ if $t_{1}<t_{1}^{*}, \mu_{1}\left(t_{1}\right)=m_{1}^{2}$ if $t_{1} \geq t_{1}^{*}, \pi\left(m_{1}^{1}\right)=\left(\hat{y}_{0} ; c, 0\right)$, $\pi\left(m_{1}^{2}\right)=z$. and $\pi\left(m_{1}\right) \in\left\{\pi\left(m_{1}^{1}\right), \pi\left(m_{1}^{2}\right)\right\}$ for $m_{1} \neq m_{1}^{1}, m_{1}^{2}$. This is an equilibrium profile.
} 
$(\tilde{y} ; c, 0) \in h\left(t_{1}^{*}, \bar{t}_{1}\right)$ and $h\left(\underline{t}_{1}, t_{1}^{*}\right) \neq\{(\tilde{y} ; c, 0)\} .{ }^{15}$ Note that a "compromise-or-fight" equilibrium is outcome equivalent to a babbling equilibrium if and only if $c=0$.

The chair is clearly better off in a size-two equilibrium than in a size-one equilibrium because she benefits from more information transmission. The comparison is less clear-cut, however, for legislator 1, just like in Matthews (1989). For example, suppose we have a size-one equilibrium with elicited proposal $(y ; x)$ and a size-two equilibrium with elicited proposals $\left(\hat{y}_{0} ; c, 0\right)$ and $\left(y^{\prime} ; x^{\prime}\right)$ where $\hat{y}_{0}<y<y^{\prime}$. Then, more extreme (either more to the left or more to the right) types of legislator 1 prefer the size-two equilibrium but the moderate types prefer the size-one equilibrium. The ex ante expected payoff of legislator 1 can go either way.

\subsection{Size-three equilibria}

The following proposition characterizes size-three equilibria.

Proposition 2. In a size-three equilibrium, the elicited proposals are $\left(\hat{y}_{0} ; c, 0\right),(y ; x)$ with $y \in\left(\hat{y}_{0}, \tilde{y}\right)$ and $x_{1} \geq 0$, and $(\tilde{y} ; c, 0)$. There exist $\tau_{1}^{*}$ and $\tau_{1}^{* *}>\tau_{1}^{*}$ such that if $t_{1}<\tau_{1}^{*}$, type $t_{1}$ elicits $\left(\hat{y}_{0} ; c, 0\right)$ and accepts it; if $\tau_{1}^{*}<t_{1}<\tau_{1}^{* *}$, type $t_{1}$ elicits $(y ; x)$ with $y \in\left(\hat{y}_{0}, \tilde{y}\right)$ and accepts it; if $t_{1}>\tau_{1}^{* *}$, type $t_{1}$ elicits $(\tilde{y} ; c, 0)$ and accepts it.

Suppose the types who elicit the same proposal send the same message, and suppose $m_{1}^{1}$ induces $\left(\hat{y}_{0} ; c, 0\right), m_{1}^{2}$ induces $(y ; x)$ with $y \in\left(\hat{y}_{0}, \tilde{y}\right)$ and $m_{1}^{3}$ induces $(\tilde{y} ; c, 0)$. We can interpret $m_{1}^{1}$ as the "cooperate" message, $m_{1}^{2}$ as the "compromise" message and $m_{1}^{3}$ as the "fight" message. When his ideology is sufficiently aligned with the chair's, legislator 1 sends $m_{1}^{1}$ to signal his willingness to vote for the chair's ideal policy and the chair responds by proposing her ideal without giving legislator 1 any private benefit. When legislator 1's ideology is somewhat aligned with the chair's, he sends $m_{1}^{2}$ and the chair responds with a compromise policy and (potentially) gives legislator 1 some private benefit. Lastly, when legislator 1 holds an ideological position distant from the chair's, he sends the message $m_{1}^{3}$ to signal a tough stance on policy change. The chair responds to it by making no policy change and giving out no private benefit.

As to existence, we can construct a size-three equilibrium from a size-two equilibrium, under certain conditions. Consider a size-two equilibrium with elicited proposals $\left(\hat{y}_{0} ; c, 0\right)$ and $(y ; x)$

\footnotetext{
${ }^{15}$ To see why the conditions are sufficient, let $\mu_{1}\left(t_{1}\right)=m_{1}^{1}$ if $t_{1}<t_{1}^{*}, \mu_{1}\left(t_{1}\right)=m_{1}^{2}$ if $t_{1} \geq t_{1}^{*}, \pi\left(m_{1}^{1}\right)=z$ for some $z \in h\left(\underline{t}_{1}, t_{1}^{*}\right) \backslash\{(\tilde{y} ; c, 0)\}, \pi\left(m_{1}^{2}\right)=(\tilde{y} ; c, 0)$ and $\pi\left(m_{1}\right) \in\left\{\pi\left(m_{1}^{1}\right), \pi\left(m_{1}^{2}\right)\right\}$ for $m_{1} \neq m_{1}^{1}, m_{1}^{2}$. This is an equilibrium profile.
} 
where $y \in\left(\hat{y}_{0}, \tilde{y}\right)$. Suppose the proposal $(y ; x)$ is rejected with positive probability. If there exists an $\varepsilon>0$ such that $(\tilde{y} ; c, 0) \in h\left(t_{1}, \bar{t}_{1}\right)$ for $t_{1}>\bar{t}_{1}-\varepsilon$ (i.e., $(\tilde{y} ; c, 0)$ is an optimal proposal for the chair when she believes $t_{1}$ is sufficiently high), then a size-three equilibrium exists. To construct it, let $\tau_{1}^{*}$ be the type indifferent between $\left(\hat{y}_{0} ; c, 0\right)$ and $(y ; x)$ and find $\tau_{1}^{* *} \in\left(\tau_{1}^{*}, \bar{t}_{1}\right)$ such that $(\tilde{y} ; c, 0) \in h\left(\tau_{1}^{* *}, \bar{t}_{1}\right)$ and type $\tau_{1}^{* *}$ is indifferent between the status quo and $(y ; x)$ (since $(y ; x)$ is rejected with positive probability in the size-two equilibrium, $\tau_{1}^{* *}$ exists). Consider the following strategy profile: $\mu_{1}\left(t_{1}\right)=m_{1}^{1}$ if $t_{1} \leq \tau_{1}^{*}, \mu_{1}\left(t_{1}\right)=m_{1}^{2}$ if $\tau_{1}^{*}<t_{1} \leq \tau_{1}^{* *}, \mu_{1}\left(t_{1}\right)=m_{1}^{3}$ if $t_{1}>\tau_{1}^{* *}, \pi\left(m_{1}^{1}\right)=\left(\hat{y}_{0} ; c, 0\right), \pi\left(m_{1}^{2}\right)=(y ; x), \pi\left(m_{1}^{3}\right)=(\tilde{y} ; c, 0)$. This generates a size-three equilibrium. Every type of legislator 1 is indifferent between the original size-two equilibrium and the constructed size-three equilibrium. When $c>0$, the chair is strictly better off in the size-three equilibrium because for $t_{1}>\tau_{1}^{* *}$, the outcome in the size-two equilibrium is $s=(\tilde{y} ; 0,0)$ whereas in the size-three equilibrium it is $(\tilde{y} ; c, 0)$.

Similarly, we can construct a size-three equilibrium from a size-two equilibrium with elicited proposals $(\tilde{y} ; c, 0)$ and $(y ; x)$ where $y \in\left(\hat{y}_{0}, \tilde{y}\right)$, under certain conditions. Suppose types who elicit $(y ; x)$ accept it in the size-two equilibrium. If $u_{1}\left(\left(\hat{y}_{0} ; c, 0\right), \underline{t}_{1}\right)>u_{1}\left((y ; x), \underline{t}_{1}\right)$ (which implies that there exists $t_{1}>\underline{t}_{1}$ such that $\left.u_{1}\left(\left(\hat{y}_{0} ; c, 0\right), t_{1}\right)=u_{1}\left((y ; x), t_{1}\right)\right)$, then we can construct a size-three equilibrium as follows. Let $\tau_{1}^{*}$ be the type such that $u_{1}\left(\left(\hat{y}_{0} ; c, 0\right), \tau_{1}^{*}\right)=u_{1}\left((y ; x), \tau_{1}^{*}\right)$ and let $\tau_{1}^{* *}$ be the type such that $u_{1}\left((y ; x), \tau_{1}^{* *}\right)=u_{1}\left(s, \tau_{1}^{* *}\right)$. Consider the following strategy

profile: $\mu_{1}\left(t_{1}\right)=m_{1}^{1}$ if $t_{1} \leq \tau_{1}^{*}, \mu_{1}\left(t_{1}\right)=m_{1}^{2}$ if $\tau_{1}^{*}<t_{1} \leq \tau_{1}^{* *}, \mu_{1}\left(t_{1}\right)=m_{1}^{3}$ if $t_{1}>\tau_{1}^{* *}$, $\pi\left(m_{1}^{1}\right)=\left(\hat{y}_{0} ; c, 0\right), \pi\left(m_{1}^{2}\right)=(y ; x), \pi\left(m_{1}^{3}\right)=(\tilde{y} ; c, 0)$. This generates a size-three equilibrium. If $t_{1} \geq \tau_{1}^{*}$, legislator 1 is indifferent between the original size-two equilibrium and the constructed size-three equilibrium, but if $t_{1}<\tau_{1}^{*}$, legislator 1 's payoff is strictly higher in the size-three equilibrium. The chair is strictly better off in the size-three equilibrium, which is more informative than the size-two equilibrium.

\subsection{Bundled bargaining versus separate bargaining}

In the bundled bargaining game considered so far, the chair makes a proposal on an ideological dimension and a distributive dimension, and the two dimensions are accepted or rejected together. An interesting question arises as to whether the chair is better off bundling the two dimensions together or negotiating them separately. Unlike in the bundled bargaining game, it is possible in the separate bargaining game that a proposal on one dimension passes while the proposal on the other dimension fails to pass. Note that in the separate bargaining game, we 
have a simple ultimatum game on the distributive dimension, and the chair proposes $(c, 0)$ and legislator 1 accepts it in equilibrium. On the ideological dimension, we have a game identical to that considered in Matthews (1989).

One advantage of bundling the ideological and the distributive dimensions together is that it affords the legislators the flexibility of trading private benefits for policy compromises. This is illustrated in Example 1 with complete information. Moreover, in a related paper, Chen and Eraslan (2012) show that if the legislators' ideological positions are known, but the weight they place on the ideological decision relative to the distributive decision is private information, then it always benefits the chair to bundle the two dimensions together. But as we show in the discussion that follows, when the legislators' ideological positions are private information, bundling has two potential disadvantages.

The first disadvantage is that by bundling the two dimensions together, the legislators risk losing the surplus $c$ if negotiation breaks down whereas no such risk exists if they bargain over the distributive dimension separately, as seen in Example 2.

Another disadvantage of bundling is the informational loss from bargaining the two dimensions together, which is relevant even if there is no risk of losing the surplus. Specifically, suppose $c=0$, so that failure to pass a proposal does not result in the dissipation of private benefits. In this case, we can interpret bundled bargaining as (the possibility of) using side payments to gain support on an ideological decision and separate bargaining as the unavailability of side payments (or, the chair commits not to use private benefit in exchange for support of ideological decisions).

Say that an equilibrium is informative if it is not outcome equivalent to a size-one equilibrium. The next proposition says that less information may be transmitted in equilibrium when the two dimensions are bundled than when they are separated, in the sense that if an informative size-two equilibrium exists in the bundled bargaining game, then such an equilibrium exists in the separate bargaining game, but the converse is not true.

Proposition 3. Suppose $c=0$. (i) If an informative size-two equilibrium exists in the bundled bargaining game, then an informative size-two equilibrium exists in the separate bargaining game. (ii) If an informative size-two equilibrium exists in the separate bargaining game, an informative size-two equilibrium may not exist in the bundled bargaining game.

As seen in Example 3, the informational loss from bundled bargaining can be significant 
enough to make it better for the chair to bargain the two dimensions separately.

\section{$5 \quad$ Two senders}

Now suppose there are two senders, legislator 1 and legislator 2. As is common in the cheaptalk literature, we focus on equilibria in which legislator $i$ 's message rule has the following partitional form: $\mu_{i}\left(t_{i}\right)=m_{i}^{k}$ if $t_{i} \in\left(\tau_{i}^{k}, \tau_{i}^{k+1}\right]\left(k=1, \ldots, K_{i}\right)$ where $\underline{t}_{i}=\tau_{i}^{1}<\tau_{i}^{2}<\ldots<$ $\tau_{i}^{K_{i}+1}=\bar{t}_{i}, m_{i}^{k} \in M_{i}$ and $m_{i}^{k} \neq m_{i}^{k^{\prime}}$ for $k \neq k^{\prime}$. Additionally, we only consider equilibria in which adjacent intervals of types elicit different distributions of proposals, i.e., if $K_{i} \geq 2$, then

for $k=1, \ldots, K_{i}-1, \pi\left(m_{i}^{k}, m_{j}\right) \neq \pi\left(m_{i}^{k+1}, m_{j}\right)$ for at least one $m_{j}$ that is sent by some type $t_{j}$. This loses no generality because if it is violated and types in some adjacent intervals elicit the same distribution of proposals, then the equilibrium is outcome equivalent to another in which types in these adjacent intervals send the same message.

We call $K_{i}$ the size of legislator $i$ 's message rule. If $K_{i}=1$, legislator $i$ "babbles" and conveys no information about his type; if $K_{i}>1$, however, then legislator $i$ conveys some information about his type.

\subsection{Equilibrium characterization}

In the following proposition, we characterize "simple equilibria." These are equilibria in which any two proposals made by the chair are independent of legislator $j$ 's messages if for each of these proposals, either legislator $j$ rejects it with probability 1 , or legislator $i$ accepts it with probability 1. That is, $\pi\left(m_{i}, m_{j}\right)=\pi\left(m_{i}, m_{j}^{\prime}\right)$ if for each of $\pi\left(m_{i}, m_{j}\right)$ and $\pi\left(m_{i}, m_{j}^{\prime}\right)$, either (i) every type of legislator $i$ who sends $m_{i}$ accepts it, or (ii) every type of legislator $j$ who send $m_{j}$ (respectively $\left.m_{j}^{\prime}\right)$ rejects $\pi\left(m_{i}, m_{j}\right)$ (respectively $\pi\left(m_{i}, m_{j}^{\prime}\right)$ ). We find the refinement of simple equilibrium reasonable because if legislator $i$ accepts a proposal with probability 1 (so that legislator $j$ is not pivotal), or if legislator $j$ rejects a proposal with probability 1 , then the chair's optimal proposal depends only on her belief about legislator $i$ 's type, which is independent of legislator $j$ 's message. Note that if the chair's optimal proposal is unique, then the requirement of simple equilibrium is automatically satisfied.

Proposition 4. Fix a simple equilibrium $(\mu, \gamma, \pi)$. A message rule for any legislator $i$ has at most size three, i.e., $K_{i} \leq 3$. For a size-three message rule $\mu_{i}(\cdot),\left(m_{i}^{1}, m_{j}\right)$ induces $\left(\hat{y}_{0} ; c, 0,0\right)$ 
for all $m_{j}$ sent in equilibrium; $\left(m_{i}^{2}, m_{j}\right)$ induces a compromise proposal with $y \in\left(\hat{y}_{0}, \tilde{y}\right)$ if $m_{j} \in\left\{m_{j}^{2}, m_{j}^{3}\right\}$; and $\left(m_{i}^{3}, m_{j}^{3}\right)$ induces $(\tilde{y} ; c, 0,0)$.

As in the one-sender case, we can interpret $m_{i}^{1}$ as the "cooperate" message, $m_{i}^{2}$ as the "compromise" message and $m_{i}^{3}$ as the "fight" message. Legislator $i$ sends $m_{i}^{1}$ only when his ideology is sufficiently aligned with the chair's. With the assurance of this cooperative ally, the chair proposes her ideal policy without giving out any private benefit. By contrast, when legislator $i$ holds a position distant from the chair's, he send $m_{i}^{3}$ to signal a tough stance on policy change. If both legislators send the "fight" message, the chair realizes that their positions are too far from her own and the best proposal is to make no policy change and give out no private benefit. Finally, when a legislator holds a position somewhat aligned with the chair's, he sends a "compromise" message and the chair responds with a policy in between the status quo and her own ideal unless the other legislator indicates willingness to cooperate.

The intuition for Proposition 4 is similar to that for Proposition 1 in the one-sender case, with the appropriate modifications. The crucial step is that for either legislator 1 or 2 , only one message sent in equilibrium induces proposals that involve compromise policies $y \in\left(\hat{y}_{0}, \tilde{y}\right)$. More precisely, if $m_{i}^{k_{i}}$ induces a proposal with policy $y \in\left(\hat{y}_{0}, \tilde{y}\right)$, then any proposal induced by $m_{i}^{k_{i}^{\prime}}$ where $k_{i}^{\prime}<k_{i}$ must be $\left(\hat{y}_{0} ; c, 0,0\right)$, the proposal that gives the chair the highest possible payoff. Together with the observation that $k_{i}=K_{i}$ if a message $m_{i}^{k_{i}}$ either induces $(\tilde{y} ; c, 0,0)$ or a proposal rejected by legislator $i$, it follows that a message rule has at most size three.

Since the message rule for each legislator has a size of up to three, there are many different types of equilibria. Instead of enumerating all of them, in what follows, we provide an extended example that illustrates what different equilibria look like. We first keep one legislator's message uninformative $\left(K_{j}=1\right)$ and vary the size of the other legislator's message rule $\left(1 \leq K_{i} \leq 3\right)$. We then characterize an equilibrium in which both legislators' messages are informative.

Example 4. Suppose $\tilde{y}=0, \hat{y}_{0}=-1, c=1, u_{i}\left(z, t_{i}\right)=x_{i}-\left(y-\hat{y}_{i}\right)^{2}$ and $\hat{y}_{i}$ (equivalently, $t_{i}$ ) is uniformly distributed on $[-2,2]$ for $i=1,2$.

Fix $K_{2}=1$, i.e, legislator 2 babbles. To lighten notation, assume that any type of legislator 2 sends $m_{2}$.

Suppose $K_{1}=1$. Calculation shows that the chair's optimal proposal is $(\tilde{y} ; c, 0,0)=$ $(0 ; 1,0,0)$. Intuitively, when both legislators babble, the chair faces a high degree of uncertainty about the legislators' positions and therefore chooses to make the safe proposal that 
maintains the status quo policy and makes no transfers.

Suppose $K_{1}=2$, i.e., $\mu_{1}\left(t_{1}\right)=m_{1}^{1}$ if $t_{1} \leq \tau_{1}^{2}, \mu_{1}\left(t_{1}\right)=m_{1}^{2}$ if $t_{1}>\tau_{1}^{2}$. Calculation shows that $\pi\left(m_{1}^{2}, m_{2}\right)=(\tilde{y} ; c, 0,0)=(0 ; 1,0,0)$, independent of the cutoff $\tau_{1}^{2}$. Corresponding to different cutoffs $\tau_{1}^{2}$, there are many equilibria in which legislator 1's message rule has size two. For instance, let $\tau_{1}^{2}=-\frac{1}{2}, \pi\left(m_{1}^{1}, m_{2}\right)=(-1 ; 1,0,0), \pi\left(m_{1}^{2}, m_{2}\right)=(0 ; 1,0,0),{ }^{16}$ which generates an equilibrium in which no compromise policy $y \in\left(\hat{y}_{0}, \tilde{y}\right)$ is ever proposed. There is also a continuum of equilibria in which a compromise policy is proposed in response to the message profile $\left(m_{1}^{1}, m_{2}\right)$. This happens when $\tau_{1}^{2}$ is in an intermediate range. For example, let $\tau_{1}^{2}=\frac{1}{5}$, $\pi\left(m_{1}^{1}, m_{2}\right)=\left(-\frac{2}{5} ; \frac{17}{25}, \frac{8}{25}, 0\right)$ and $\pi\left(m_{1}^{2}, m_{2}\right)=(0 ; 1,0,0)$, which generates an equilibrium in which a compromise policy $y=-\frac{2}{5}$ is proposed in response to $\left(m_{1}^{1}, m_{2}\right)$. As to the players' welfare, the chair is clearly better off when $K_{1}=2$ than when $K_{1}=1$ because more information is transmitted when $K_{1}=2$. Legislator 1 is also better off in the equilibrium with $K_{1}=2$. In particular, when $t_{1}<\tau_{1}^{2}$, legislator 1 is strictly better off (i.e., when his position is close enough to the chair's position, legislator 1 is better off conveying that information to the chair). The uninformative legislator 2 , on the other hand, is worse off in the equilibrium with $K_{1}=2$.

Suppose $K_{1}=3$, i.e., $\mu_{1}\left(t_{1}\right)=m_{1}^{1}$ if $t_{1} \leq \tau_{1}^{2}, \mu_{1}\left(t_{1}\right)=m_{1}^{2}$ if $\tau_{1}^{2}<t_{1} \leq \tau_{1}^{3}$ and $\mu_{1}\left(t_{1}\right)=m_{1}^{3}$ if $t_{1}>\tau_{1}^{3}$. As shown in Proposition $4,\left(m_{1}^{1}, m_{2}\right)$ induces $\left(\hat{y}_{0} ; c, 0,0\right),\left(m_{1}^{2}, m_{2}\right)$ induces $(y ; x)$ with $y \in\left(\hat{y}_{0}, \tilde{y}\right)$ and $\left(m_{1}^{3}, m_{2}\right)$ induces $(\tilde{y} ; c, 0,0)$. There is again a continuum of equilibria. We can construct an equilibrium with $K_{1}=3$ from an equilibrium with $K_{1}=2$. For example, consider the equilibrium in the previous paragraph with $K_{1}=2$ and the elicited proposals $\left(-\frac{2}{5} ; \frac{17}{25}, \frac{8}{25}, 0\right)$ and $(0 ; 1,0,0)$. Now let $\tau_{1}^{2}=-\frac{29}{20}, \tau_{1}^{3}=\frac{1}{5}, \pi\left(m_{1}^{1}, m_{2}\right)=(-1 ; 1,0,0)$, $\pi\left(m_{1}^{2}, m_{2}\right)=\left(-\frac{2}{5} ; \frac{17}{25}, \frac{8}{25}, 0\right)$ and $\pi\left(m_{1}^{3}, m_{2}\right)=(0 ; 1,0,0)$. Comparing this equilibrium with $K_{1}=3$ to the equilibrium with $K_{1}=2$ from which it was constructed, the chair is better off in the equilibrium with $K_{1}=3$ because more information is transmitted. Legislator 1 is also better off conveying more information about his type. In particular, when his position is closely aligned with the chair's $\left(t_{1}<\tau_{1}^{1}=-\frac{29}{30}\right)$, legislator 1 is strictly better off, but legislator 2 is worse off in the equilibrium with $K_{1}=3$.

There are also equilibria in which both legislators' messages are informative. To illustrate, consider the following strategy profile with $K_{1}=K_{2}=3$. Legislator $i$ 's message rule is $\mu_{i}\left(t_{i}\right)=m_{i}^{1}$ if $t_{i} \in\left[\tau_{i}^{1}, \tau_{i}^{2}\right], \mu_{i}\left(t_{i}\right)=m_{i}^{2}$ if $t \in\left(\tau_{i}^{2}, \tau_{i}^{3}\right]$ and $\mu_{i}\left(t_{i}\right)=m_{i}^{3}$ if $\left(\tau_{i}^{3}, \tau_{i}^{4}\right]$ where

\footnotetext{
${ }^{16}$ For this equilibrium and others, we assume that for any message profile $m$ off the equilibrium path, $\pi(m)$ is equal to one of the proposals on the equilibrium path.
} 
$\tau_{i}^{1}=-2<\tau_{i}^{2}<\tau_{i}^{3}<\tau_{i}^{4}=2$. The chair's strategy is as follows: if $m_{i}=m_{i}^{1}$ for either $i=1$ or 2 , propose $(-1 ; 1,0,0)$; if $m_{i}=m_{i}^{3}$ for both $i=1,2$, propose $(0 ; 1,0,0)$; if $m_{1}=m_{1}^{2}$ and $m_{2}=m_{2}^{3}$, propose $\left(y^{\prime} ; x_{0}^{\prime}, 1-x_{0}^{\prime}, 0\right)$; if $m_{1}=m_{1}^{3}$ and $m_{2}=m_{2}^{2}$, propose $\left(y^{\prime} ; x_{0}^{\prime}, 0,1-x_{0}^{\prime}\right)$; if $m_{i}=m_{i}^{2}$ for both $i=1,2$, propose $\left(y^{\prime \prime} ; x_{0}^{\prime \prime}, 1-x_{0}^{\prime \prime}, 0\right)$ with probability $\frac{1}{2}$ and propose $\left(y^{\prime \prime} ; x_{0}^{\prime \prime}, 0,1-x_{0}^{\prime \prime}\right)$ with probability $\frac{1}{2} \cdot{ }^{17}$ Using the indifference conditions of type $\tau_{i}^{2}$ and type $\tau_{i}^{3}$ and conditions for the chair's proposals to be optimal, we find that $\tau_{i}^{2}=-0.80, \tau_{i}^{3}=0.54, y^{\prime}=-0.23, x_{0}^{\prime}=0.70, y^{\prime \prime}=$ $-0.45, x_{0}^{\prime \prime}=0.87$.

In this equilibrium, if at least one of the legislators signals his willingness to cooperate by sending message $m_{i}^{1}$, then the chair proposes her ideal $\hat{y}_{0}$ and hands out no private benefit. Because legislator $i$ 's ideal is in $\left[\tau_{i}^{1}, \tau_{i}^{2}\right]=[-2,-0.80]$, he is willing to accept the chair's ideal policy even without receiving any private benefit, and this proposal passes with probability 1 .

If both legislators act tough and send the "fight" message $m_{i}^{3}$, then the chair proposes the status quo policy $\tilde{y}$ and still hands out no private benefit. Since both legislators' ideal points are too distant from the chair's, it is too costly (i.e., the private benefits needed in exchange for their votes are too large) for it to be optimal for the chair to try to make any policy change. This proposal also passes with probability 1.

If legislator $i$ signals willingness to compromise by sending $m_{i}^{2}$ while legislator $j$ sends the fight message $m_{j}^{3}$, then the chair tries to gain the vote from legislator $i$ while giving up on legislator $j$. She proposes a compromise policy $\left(y^{\prime}=-0.23\right)$ and gives some private benefit only to legislator $i\left(x_{i}^{\prime}=0.30\right.$ and $\left.x_{j}^{\prime}=0\right)$. The proposal is rejected by legislator $j$, but is accepted by legislator $i$.

Perhaps the most interesting case is when both legislators signal willingness to compromise by sending $m_{i}^{2}$. In the equilibrium we constructed, it is equally costly (in expectation) for the chair to win the vote of either legislator. So she randomizes with equal probability between two proposals that involve the same policy $\left(y^{\prime \prime}=-0.45\right)$ and the same private benefit for herself $\left(x_{0}^{\prime \prime}=0.87\right)$, but differ with respect to which legislator receives some private benefit. Compared with the case in which only one legislator signals willingness to compromise while the other shows a tough stand, here the compromise policy is even closer to the chair's ideal and the

\footnotetext{
${ }^{17}$ Notice that we have not allowed randomization for the chair so far. Since the players are symmetric in this example, we allow randomization over who to include in the proposal when the chair is indifferent. Allowing this kind of randomization does not affect our general results. For example, for the proof of Proposition 4, the crucial step is part (ii) of Lemma 2. It can be easily verified that it still holds even if we allow randomization over which legislator to include in a proposal.
} 
private benefit that the chair gives out is also smaller. Intuitively, since the chair needs only one vote to have a proposal passed when both legislators signal willingness to compromise, they create competition between themselves and therefore the chair's optimal proposal involves less ideological compromise and less distributive concession. Interestingly, the legislator who gets no private benefit still votes for the proposal with positive probability in equilibrium. To see this, suppose $x_{i}^{\prime \prime}>0$ and $x_{j}^{\prime \prime}=0$. Then legislator $i$ votes for the proposal if $x_{i}^{\prime \prime}+\theta_{i} v\left(y^{\prime \prime}, t_{i}\right) \geq \theta_{i} v\left(\tilde{y}, t_{i}\right)$, i.e., if $t_{i} \in[-0.80,-0.08]$ and legislator $j$ votes for the proposal if $\theta_{j} v\left(y^{\prime \prime}, t_{j}\right) \geq \theta_{j} v\left(\tilde{y}, t_{j}\right)$, i.e., if $t_{j} \in[-0.80,-0.22]$. So both legislators accept the proposal with positive probability, although the probability that legislator $j$ accepts the proposal is lower compared to legislator $i$. Note that this proposal is rejected with positive probability in equilibrium.

To compare this equilibrium in which both legislators' message rules are informative with the babbling equilibrium, note that since the chair always benefits from more information transmission, her expected payoff is higher in the informative equilibrium. Both legislators 1 and 2 also have higher expected payoffs in the informative equilibrium $(-2.66)$ than they do in the babbling equilibrium $(-2.67)$, so they also benefit from more information transmission. ${ }^{18}$

\subsection{Disadvantages of bundled bargaining}

As our analysis of the one-sender game in Section 4.4 shows, although bundling the ideological and the distributive dimensions affords the legislators the flexibility of trading private benefits for policy compromises, bundling has some disadvantages as well, making it sometimes better to negotiate the two dimensions separately. Although general propositions are hard to derive, in what follows, we show that the results regarding the disadvantages of bundled bargaining are robust when we extend the model to two senders.

Recall that if $c>0$, i.e., a positive surplus is created when the players reach agreement, then the players risk losing the surplus $c$ if negotiation breaks down in the bundled bargaining game whereas they incur no such risk if they bargain over the different dimensions separately. To illustrate this in the two-sender game, suppose the parameters are the same as in Example 4, where we analyzed the "bundled bargaining" game. Now consider the alternative "separate bargaining" game in which the chair, after receiving the legislators' messages, makes one proposal on the ideological dimension and another on the distributive dimension. Then the

\footnotetext{
${ }^{18}$ We do not have a general result regarding the welfare comparison of legislators 1 and 2 across equilibria, but given what we know from the one-sender case, suspect that it is not clear cut.
} 
legislators vote on each proposal and majority rule determines whether the proposal passes in each dimension. In this separate bargaining game, the chair proposes $(c, 0,0)$ on the distributive dimension and the proposal passes. As to the ideological dimension, the following informative equilibrium exists: ${ }^{19}$ Both legislators 1 and 2 play the message rule such that $\mu_{i}\left(t_{i}\right)=m_{i}^{1}$ if $t \in\left[-2, \tau_{i}^{2}\right], \mu_{i}\left(t_{i}\right)=m_{i}^{2}$ if $t \in\left(\tau_{i}^{2}, 2\right]$ where $\tau_{i}^{2}=-0.81$. The chair proposes $y=\hat{y}_{0}$ if at least one legislator sends $m_{i}^{1}$ and a compromise policy $y=-0.62$ if both legislators send $m_{i}^{2}$. Legislator $i$ votes for the compromise policy if and only if $t_{i} \leq-0.31$. Calculation shows that the chair's expected equilibrium payoff (0.64) in the separate bargaining game is higher than her expected payoff (0.56) in the equilibrium of the bundled bargaining game described earlier with $K_{1}=K_{2}=3$. The reduction of payoff from bundling comes from the dissipation of private benefits when the legislators fail to reach an agreement, which happens when both legislators send $m_{i}^{2}$ but vote against the chair's proposal. Although failure to reach an agreement also happens even if the legislators negotiate the ideological dimension separately, the distributive dimension is shielded from such failure.

Even if $c=0$ and there is no risk of losing any surplus from bundled bargaining, separate bargaining can still be better than bundled bargaining because of the informational loss resulting from bundling. To illustrate, suppose $c=0$ but keep all the other parameters the same as in Example 4. As shown in the previous paragraph, if no side payments are allowed, then there exists an informative equilibrium in which the legislators send $m_{i}^{1}$ if $t_{i}$ is below $\tau_{i}^{2}$ and send $m_{i}^{2}$ if $t_{i}$ is above $\tau_{i}^{2}$. As in the game with one sender, when side payments are allowed, however, this is no longer an equilibrium strategy if the chair places a relatively low weight on the distributive dimension. Because of this informational loss, the chair's equilibrium payoff may be lower in the bundled bargaining game where side payments are allowed. So, when the information about the players' uncertain ideological positions is sufficiently valuable, the chair may optimally choose to commit not to use transfers to make deals on policy change in order to extract more information from communication.

19 The separate bargaining game on the ideological dimension is similar to Matthews (1989), only with three players instead of two. We can modify the argument provided in Matthews (1989) to show that each legislator's message rule has at most size two. Since the analysis does not provide much new insight, we omit the details. 


\section{Concluding remarks}

In this paper, we develop a model of legislative bargaining over an ideological issue and a distributive issue in which legislators are privately informed about their preferences. Legislators can potentially convey information about their preferences through cheap talk before a bill is proposed. In contrast to a perfect information environment, we show that it might be better to bargain over the two issues separately rather than together since bundling may result in significant informational loss. Thus our results point out another potential harm of pork barrel spending that was previously overlooked.

In our model we assumed a one-shot process with monopoly agenda control in a similar spirit to closed rule in Gilligan and Krehbiel (1987, 1989). One extension is to allow the chair to make additional proposals when the initial proposal is rejected. With discounting, we conjecture that costly delay allows the legislators to signal their types by rejecting proposals, so there could be additional information revelation over time. As in our model, we expect that bundling the two issues would result in informational loss in this setup. Another possible extension is to change the monopoly agenda control assumption, and consider a Baron-Ferejohn type bargaining protocol. We leave this extension for future work.

\section{References}

[1] D. Austen-Smith. and J. S. Banks. "Elections, Coalitions, and Legislative Outcomes," American Political Science Review 82 , 405-422, 1988.

[2] J. S. Banks and J. Duggan. "A Bargaining Model of Collective Choice," American Political Science Review, 94, 73-88, 2006.

[3] D. P. Baron and J. A. Ferejohn. "Bargaining in Legislatures," American Political Science Review, 83, 1181-1206, 1989.

[4] A. Chakraborty and R. Harbaugh. "Cheap Talk Comparisons in Multi-issue Bargaining," Economic Letters, 78, 357-363, 2003.

[5] Y. Chen and H. Eraslan. "Rhetoric in Legislative Bargaining with Asymmetric Information," working paper, 2012. 
[6] V. Crawford and J. Sobel. "Strategic Information Transmission", Econometrica 50, 6, 1431-1451, 1982.

[7] D. Diermeier and A. Merlo. "Government Turnover in Parliamentary Democracies," Journal of Economic Theory, 94, 46-90, 2000.

[8] J. Farrell and R. Gibbons. "Cheap Talk Can Matter in Bargaining," Journal of Economic Theory, 48, 221-237, 1989.

[9] T. Gilligan and K. Krehbiel. "Collective Decisionmaking and Standing Committees: An Informational Rationale for Restrictive Amendment Procedures," Journal of Law, Economics, \& Organization 3, 2, 287-335, 1987.

[10] T. Gilligan and K. Krehbiel. "Asymmetric Information and Legislative Rules with a Heterogeneous Committee," American Journal of Political Science 33, 2, 459-490, 1989.

[11] B. Harstad. "Harmonization and Side Payments in Political Cooperation." American Economic Review, 97, 3, 871-889, 2007.

[12] M. Jackson and B. Moselle. "Coalition and Party Formation in a Legislative Voting Game." Journal of Economic Theory, 103, 49-87, 2002.

[13] V. Krishna and J. Morgan. "Asymmetric Information and Legislative Rules." American Political Science Review 95, 2, 435-452, 2001.

[14] S. Matthews. "Veto Threats: Rhetoric in a Bargaining Game," Quarterly Journal of Economics, 104, 2, 347-369, 1989.

[15] S. Matthews and A. Postlewaite. "Pre-play Communication in Two-Person Sealed-Bid Double Auctions," Journal of Economic Theory, 48, 1, 238-263, 1989.

[16] P. Milgrom and C. Shannon. "Monotone Comparative Statics," Econometrica, 62, 1, 157$180,1994$. 


\section{Appendix}

Proof of Lemma 1. Suppose $u_{i}\left(z^{\prime}, t_{1}\right) \geq u_{i}\left(z, t_{1}\right)$. Then $x_{i}^{\prime}+\theta_{i} v\left(y^{\prime}, t_{1}\right) \geq x_{i}+\theta_{i} v\left(y, t_{1}\right)$, i.e., $\theta_{i}\left(v\left(y^{\prime}, t_{1}\right)-v\left(y, t_{1}\right)\right) \geq x_{i}-x_{i}^{\prime}$. Since $v(\cdot, \cdot)$ is supermodular in $\left(y, t_{1}\right)$, if $t_{1}^{\prime}>t_{1}$, then $v\left(y^{\prime}, t_{1}^{\prime}\right)-v\left(y, t_{1}^{\prime}\right)>v\left(y^{\prime}, t_{1}\right)-v\left(y, t_{1}\right)$, which implies that $\theta_{i}\left(v\left(y^{\prime}, t_{1}^{\prime}\right)-v\left(y, t_{1}^{\prime}\right)\right)>$ $\theta_{i}\left(v\left(y^{\prime}, t_{1}\right)-v\left(y, t_{1}\right)\right) \geq x_{i}-x_{i}^{\prime}$. Hence $u_{i}\left(z^{\prime}, t_{1}^{\prime}\right)>u_{i}\left(z, t_{1}^{\prime}\right)$ for $t_{1}^{\prime}>t_{1}$. A similar argument proves the second part of the claim.

Proof of Proposition 1. Part (i) follows from parts (ii) and (iii), so it suffices to prove parts (ii) and (iii).

Part (ii): Since the proposal $(\tilde{y} ; c, 0)$ is accepted with probability $1, v\left(y, \hat{y}_{0}\right)$ reaches its maximum at $y=\hat{y}_{0}$, and $v_{11}<0$, any proposal with $y>\tilde{y}$ is not optimal for the chair. Hence, if $z$ is elicited in equilibrium, then it satisfies $y \leq \tilde{y}$. Suppose $y=\tilde{y}$, but $x \neq(c, 0)$. Then $x_{1}>0$ and legislator 1 accepts $z$. But there exists another proposal $z^{\prime}=\left(\tilde{y} ; x^{\prime}\right)$ with $0<x_{1}^{\prime}<x_{1}$ such that legislator 1 still accepts $z^{\prime}$. Since the chair strictly prefers $z^{\prime}$ to $z$, this is a contradiction.

To prove part (iii), suppose both $z=(y ; x)$ and $z^{\prime}=\left(y^{\prime} ; x^{\prime}\right)$ are elicited in equilibrium with $y<y^{\prime}<\tilde{y}$. We next show that $z=\left(\hat{y}_{0} ; c, 0\right)$. Since both $z$ and $z^{\prime}$ are elicited in equilibrium, there exists a type, $\tilde{t}_{1}$, who is indifferent between $z$ and $z^{\prime}$. By Lemma 1 , any type $t_{1}>\tilde{t}_{1}$ strictly prefers $z^{\prime}$ to $z$ and hence does not elicit $z$, and any type $t_{1}<\tilde{t}_{1}$ strictly prefers $z$ to $z^{\prime}$ and hence does not elicit $z^{\prime}$. So only types $t_{1} \geq \tilde{t}_{1}$ elicit $z^{\prime}$. Since $z^{\prime}$ is elicited in equilibrium and therefore accepted by some types that elicit it, there exists a type $t_{1}^{\dagger} \geq \tilde{t}_{1}$ such that $u_{1}\left(z^{\prime}, t_{1}^{\dagger}\right) \geq$ $u_{1}\left(s, t_{1}^{\dagger}\right)$. Since $y^{\prime}<\tilde{y}$, it follows from Lemma 1 that $u_{1}\left(z^{\prime}, \tilde{t}_{1}\right) \geq u_{1}\left(s, \tilde{t}_{1}\right)$. Together with $u_{1}\left(z, \tilde{t}_{1}\right)=u_{1}\left(z^{\prime}, \tilde{t}_{1}\right)$ and Lemma 1 , this implies that $u_{1}\left(z, t_{1}\right)>u_{1}\left(z^{\prime}, t_{1}\right)>u_{1}\left(s, t_{1}\right)$ for any $t_{1}<\tilde{t}_{1}$.

Suppose $z \neq\left(\hat{y}_{0} ; c, 0\right)$. Consider the following two possibilities: (i) Suppose $x_{1}>0$. Since $u_{1}\left(z, t_{1}\right)>u_{1}\left(s, t_{1}\right)$ for any $t_{1}<\tilde{t}_{1}$, and $u_{1}$ is continuous in $x_{1}$ for any $t_{1}$, there exists $\varepsilon \in\left(0, x_{1}\right)$ such that for any $x_{1}^{\prime \prime}>x_{1}-\varepsilon>0$, the proposal $\left(y ; c-x_{1}^{\prime \prime}, x_{1}^{\prime \prime}\right)$ is accepted by any type $t_{1} \leq \tilde{t}_{1}$. Since $u_{0}\left(y ; c-x_{1}^{\prime \prime}, x_{1}^{\prime \prime}\right)>u_{0}(z), z$ is not optimal for the chair, a contradiction. (ii) Suppose $y \neq \hat{y}_{0}$. Since $\hat{y}_{0}<\tilde{y}, \hat{y}_{0}<\hat{y}_{1}, v\left(y, \hat{y}_{i}\right)$ reaches its maximum at $y=\hat{y}_{i}$, and $v_{11}<0$, we must have $y \geq \hat{y}_{0}$. Since $u_{1}\left(z, t_{1}\right)>u_{1}\left(s, t_{1}\right)$ for any $t_{1}<\tilde{t}_{1}$, it follows that if $y>\hat{y}_{0}$, there exists $\varepsilon \in\left(0, y-\hat{y}_{0}\right)$ such that for any $y^{\prime \prime} \in\left(\hat{y}_{0}, y-\varepsilon\right)$, the proposal $\left(y^{\prime \prime} ; x\right)$ is accepted by any type $t_{1} \leq \tilde{t}_{1}$. Since $u_{0}\left(y^{\prime \prime} ; x\right)>u_{0}(z), z$ is not optimal for the chair, a contradiction.

Given parts (ii) and (iii), it follows that an equilibrium has at most size three. 
Proof of Proposition 2. Proposition 1 implies that there are at most three proposals elicited in equilibrium: $\left(\hat{y}_{0} ; c, 0\right),(\tilde{y} ; c, 0)$ and $\left(y ; c-x_{1}, x_{1}\right)$ with $y \in\left(\hat{y}_{0}, \tilde{y}\right)$. Moreover, Lemma 1 implies that there exist a $\tau_{1}^{*}$ and a $\tau_{1}^{* *}$ with $\tau_{1}^{*}<\tau_{1}^{* *}$ such that among the elicitable proposals, type $t_{1}$ strictly prefers $\left(\hat{y}_{0} ; c, 0\right)$ if $t_{1}<\tau_{1}^{*}$, type $t_{1}$ strictly prefers $\left(y ; c-x_{1}, x_{1}\right)$ if $\tau_{1}^{*}<t_{1}<\tau_{1}^{* *}$ and type $t_{1}$ strictly prefers $(\tilde{y} ; c, 0)$ if $t_{1}>\tau_{1}^{* *}$. Hence, if $t_{1}<\tau_{1}^{*}$, type $t_{1}$ elicits $\left(\hat{y}_{0} ; c, 0\right)$ and accept it; if $\tau_{1}^{*}<t_{1}<\tau_{1}^{* *}$, type $t_{1}$ elicits $\left(y ; c-x_{1}, x_{1}\right)$ and accepts it and if $t_{1}>\tau_{1}^{* *}$, type $t_{1}$ elicits $(\tilde{y} ; c, 0)$ and accepts it.

Proof of Proposition 3. Part (i): Recall that $h\left(t_{1}^{\prime}, t_{1}^{\prime \prime}\right)$ is the set of optimal proposals for the chair in the bundled bargaining game when she knows that $t_{1} \in\left[t_{1}^{\prime}, t_{1}^{\prime \prime}\right]$.

Since $c=0$, if an informative size-two equilibrium exists in the bundled bargaining game, there exists a type $\tau_{1}^{*}$ such that $u_{1}\left(\left(\hat{y}_{0} ; 0,0\right), \tau_{1}^{*}\right)=u_{1}\left(z^{\prime}, \tau_{1}^{*}\right)$ where $z^{\prime}=\left(y^{\prime} ; x^{\prime}\right) \in h\left(\tau_{1}^{*}, \bar{t}_{1}\right)$ with $y^{\prime}>\hat{y}_{0}$. Since $x_{1}^{\prime} \geq 0$, it follows that $v\left(\hat{y}_{0}, \tau_{1}^{*}\right) \geq v\left(y^{\prime}, \tau_{1}^{*}\right)$.

For any $a \in T_{1}$, let $g(a)$ be the set of optimal proposals on the ideological dimension for the chair when she knows that $t_{1} \in\left[a, \bar{t}_{1}\right]$, with the constraint that $x_{1}=0$.

For any $z=\left(y ;-x_{1}, x_{1}\right) \in Z$, let $k(z)$ be the rightmost type in $\left[\tau_{1}^{*}, \bar{y}_{1}\right]$ willing to accept $z$ if some type in $\left[\tau_{1}^{*}, \bar{y}_{1}\right]$ is willing to accept $z$ and let $k(z)=\tau_{1}^{*}$ otherwise. Also, let $W\left(y, x_{1}\right)=$ $\left(-x_{1}+v\left(y, \hat{y}_{0}\right)\right) A+v\left(\tilde{y}, \hat{y}_{0}\right)(1-A)$ where $A=\left(F_{1}(k(z))-F_{1}\left(\tau_{1}^{*}\right)\right) /\left(F_{1}\left(\bar{t}_{1}\right)-F_{1}\left(\tau_{1}^{*}\right)\right)$. That is, $W\left(y, x_{1}\right)$ is the chair's expected payoff by proposing $z$ when $t_{1} \in\left[\tau_{1}^{*}, \bar{t}_{1}\right]$. Since $\left(y^{\prime} ; x^{\prime}\right) \in$ $h\left(\tau_{1}^{*}, \bar{t}_{1}\right)$, it follows that $y^{\prime} \in \arg \max _{y \in Y} W\left(y, x_{1}^{\prime}\right)$. Also, by the definition of $g$, we have $g\left(\tau_{1}^{*}\right)=$ $\arg \max _{y \in Y} W(y, 0)$.

Note that

$$
\frac{\partial W^{2}}{\partial y \partial x_{1}}=-\frac{\partial A}{\partial y}
$$

Since $\frac{\partial A}{\partial y}$ has the same sign as $\frac{\partial k(z)}{\partial y}$, and $\frac{\partial k(z)}{\partial y} \geq 0$ for any $y \leq \tilde{y}$, it follows that $\frac{\partial W^{2}}{\partial y \partial x_{1}} \leq 0$ for $y \leq \tilde{y}$. Standard results from monotone comparative statics (see, for example, Milgrom and Shannon 1994, Theorem 4) imply that there exists a $y^{\dagger} \in g\left(\tau_{1}^{*}\right)$ such that $y^{\dagger} \geq y^{\prime}$. As shown earlier, $v\left(\hat{y}_{0}, \tau_{1}^{*}\right) \geq v\left(y^{\prime}, \tau_{1}^{*}\right)$. Since $y^{\dagger} \geq y^{\prime}>\hat{y}_{0}$ and $v$ is strictly concave in $y$, it follows that $v\left(\hat{y}_{0}, \tau_{1}^{*}\right) \geq v\left(y^{\prime}, \tau_{1}^{*}\right) \geq v\left(y^{\dagger}, \tau_{1}^{*}\right)$. By Proposition 3 (page 358) in Matthews (1989), an informative size-two equilibrium exists in the separate bargaining game.

Part (ii): Example 3 shows that part (ii) is true.

Proof of Proposition 4. To prove the proposition we establish the following lemmas. 
Lemma 2. Fix a simple equilibrium $(\mu, \gamma, \pi)$. Suppose $z=(y ; x)$ with $y<\tilde{y}$ is induced by $\left(m_{1}^{k_{1}}, m_{2}^{k_{2}}\right)$ and accepted with positive probability by legislator $i$. Then, for $i=1,2$, (i) type $\tau_{i}^{k_{i}}$ of legislator $i$ strictly prefers $z$ to the status quo. (ii) if $k_{i} \geq 2$, then $\pi\left(m_{i}^{k_{i}-1}, m_{j}\right)=\left(\hat{y}_{0} ; c, 0,0\right)$ for any $m_{j} \in\left\{m_{j}^{1}, m_{j}^{2}, \ldots, m_{j}^{K_{j}}\right\}$.

Proof. Part $(i)$ : Suppose to the contrary that type $\tau_{i}^{k_{i}}$ weakly prefers $s$ to $z$. Since $y<\tilde{y}$, by Lemma 1 , if $t_{i}>\tau_{i}^{k_{i}}$, then type $t_{i}$ strictly prefer $s$ to $z$ and hence rejects $(y ; x)$. Since $m_{i}^{k_{i}}$ is sent by $t_{i} \in\left(\tau_{i}^{k_{i}}, \tau_{i}^{k_{i}+1}\right]$, this contradicts the assumption that $(y ; x)$ is accepted by legislator $i$ with positive probability.

Part $(i i)$ : Suppose to the contrary that $\pi\left(m_{i}^{k_{i}-1}, m_{j}\right) \neq\left(\hat{y}_{0} ; c, 0,0\right)$ for at least one $m_{j} \in$ $\left\{m_{j}^{1}, m_{j}^{2}, \ldots, m_{j}^{K_{j}}\right\}$. Among these proposals find one that gives type $\tau_{i}^{k_{i}}$ the highest payoff, and denote it by $z^{\prime}=\left(y^{\prime} ; x^{\prime}\right)$. Consider the following two cases.

(a) Suppose type $\tau_{i}^{k_{i}}$ weakly prefers $\left(\hat{y}_{0} ; c, 0,0\right)$ to $\left(y^{\prime} ; x^{\prime}\right)$. Since $y^{\prime} \leq \tilde{y}, x_{i}^{\prime} \geq 0$, and $v_{11}\left(y, \tau_{i}^{k_{i}}\right)<0$, it follows that type $\tau_{i}^{k_{i}}$ weakly prefers $\left(\hat{y}_{0} ; c, 0,0\right)$ to $s$. By Lemma 1 , for any type $t_{i}<\tau_{i}^{k_{i}}$, legislator $i$ strictly prefers $\left(\hat{y}_{0} ; c, 0,0\right)$ to $s$ and therefore accepts it. Since $\left(\hat{y}_{0} ; c, 0,0\right)$ gives the chair the highest possible payoff, her optimal response to any $m$ with $m_{i}=m_{i}^{k_{i}-1}$ must be $\left(\hat{y}_{0} ; c, 0,0\right)$, a contradiction.

(b) Suppose type $\tau_{i}^{k_{i}}$ strictly prefers $\left(y^{\prime} ; x^{\prime}\right)$ to $\left(\hat{y}_{0} ; c, 0,0\right)$. Then $\left(y^{\prime} ; x^{\prime}\right)$ is the proposal among those induced by $m_{i}^{k_{i}-1}$ that gives type $\tau_{i}^{k_{i}}$ the highest payoff. Since type $\tau_{i}^{k_{i}}$ is indifferent between sending $m_{i}^{k_{i}}$ and $m_{i}^{k_{i}-1}$, and $\left(m_{i}^{k_{i}}, m_{j}\right)$ induces a proposal that type $\tau_{i}^{k_{i}}$ accepts for at least one $m_{j}$ sent in equilibrium, it follows that $\left(m_{i}^{k_{i}-1}, m_{j}\right)$ also induces a proposal that type $\tau_{i}^{k_{i}}$ accepts for at least one $m_{j}$ sent in equilibrium. Hence type $\tau_{i}^{k_{i}}$ prefers $\left(y^{\prime} ; x^{\prime}\right)$ to $s$. By Lemma 1 , any type $t_{i} \leq \tau_{i}^{k}$ strictly prefers $\left(y^{\prime} ; x^{\prime}\right)$ to $s$. Since $\left(y^{\prime} ; x^{\prime}\right) \neq\left(\hat{y}_{0} ; c, 0,0\right)$, there exists another proposal $\left(y^{\prime \prime} ; x^{\prime \prime}\right)$ with either $\hat{y}_{0} \leq y^{\prime \prime}<y^{\prime}$ or $x_{i}^{\prime \prime}<x_{i}^{\prime}$ such that legislator $i$ with $t_{i} \leq \tau_{i}^{k}$ strictly prefers $\left(y^{\prime \prime} ; x^{\prime \prime}\right)$ to $s$ and hence accepts it. Since the chair strictly prefers $\left(y^{\prime \prime} ; x^{\prime \prime}\right)$ to $\left(y^{\prime} ; x^{\prime}\right),\left(y^{\prime} ; x^{\prime}\right)$ is not a best response, a contradiction.

Let $\tilde{k}_{i}$ be the maximum $k \in K_{i}$ such that $\pi\left(m_{i}^{k}, m_{j}\right) \neq(\tilde{y} ; c, 0,0)$ for some $m_{j} \in\left\{m_{j}^{1}, m_{j}^{2}, \ldots, m_{j}^{K_{j}}\right\}$ and legislator $i$ accepts $\pi\left(m_{i}^{k}, m_{j}\right)$ with positive probability.

Since we assume that adjacent intervals of types induce different distributions of proposals, Lemma 2 implies that $\tilde{k}_{i} \leq 2$ since for any $m_{j} \in\left\{m_{j}^{1}, m_{j}^{2}, \ldots, m_{j}^{K_{j}}\right\}$, the message profile $\left(m_{i}^{k}, m_{j}\right)$ with $k<\tilde{k}_{i}$ induces $\left(\hat{y}_{0} ; c, 0,0\right)$. 
Lemma 3. Fix a simple equilibrium $(\mu, \gamma, \pi)$. Let $m_{j} \in\left\{m_{j}^{1}, m_{j}^{2}, \ldots, m_{j}^{K_{j}}\right\}$. Suppose $\left(m_{i}^{k}, m_{j}\right)$ either induces $(\tilde{y} ; c, 0,0)$ or induces a proposal that is rejected by legislator $i$ with probability 1 in $(\mu, \gamma, \pi)$. Then $k=K_{i}$.

Proof. Suppose to the contrary that $k<K_{i}$. Let $(y ; x)$ be a proposal induced by $\left(m_{i}^{k+1}, m_{j}\right)$ for some $m_{j} \in\left\{m_{j}^{1}, m_{j}^{2}, \ldots, m_{j}^{K_{j}}\right\}$ and suppose $(y ; x)$ is accepted by legislator $i$ with positive probability. If $y<\tilde{y}$, then by Lemma $2,\left(m_{i}^{k}, m_{j}\right)$ induces $\left(\hat{y}_{0} ; c, 0,0\right)$ for any $m_{j}$ sent in equilibrium, a contradiction. Hence $(y ; x)=(\tilde{y} ; c, 0,0)$, which implies that a proposal induced by $m_{i}^{k+1}$ must either be $(\tilde{y} ; c, 0,0)$ or rejected by legislator $i$. Note that in a simple equilibrium, if $\pi\left(m_{i}^{k}, m_{j}\right)$ and $\pi\left(m_{i}^{k+1}, m_{j}\right)$ are both rejected by legislator $i$ with probability 1 , then $\pi\left(m_{i}^{k}, m_{j}\right)=\pi\left(m_{i}^{k+1}, m_{j}\right)$. Hence messages $m_{i}^{k}$ and $m_{i}^{k+1}$ induce the same distribution of proposals, a contradiction.

Lemma 3 implies that there is at most one message $m_{i}^{k}$ sent in equilibrium with $k>\tilde{k}_{i}$. Since $\tilde{k}_{i} \leq 2$, the maximum number of equilibrium messages for legislator $i$ is 3 , i.e., $K_{i} \leq 3$. The rest of Proposition 4 also follows from Lemma 2 and Lemma 3. 